\title{
Chemistry of Minor Groove Binder-Oligonucleotide Conjugates
}

The interaction of minor groove binder molecules (MBs) with double-stranded DNA (dsDNA) is a rich area of chemistry. The synthetic chemistry, biochemistry, molecular biology, and medicinal chemistry of MBs have been developed, and much is known about their DNA binding mechanisms. The antibiotic activity of naturally occurring MBs has prompted the development and examination of many synthetic analogs.

Generally, MBs are planar, polyaromatic molecules that can form crescent-shaped conformations in aqueous solution. Figure 8.4.1 shows examples of several types of MB structures that are described later in this unit (see Types of MB-ODNs). The strongest-binding MBs are isohelical with the minor groove formed in B-form DNA duplexes, and are stabilized by hydrophobic interactions, van der Waals forces, or hydrogen bonds to nucleotide bases in the floor of the groove. MBs can have high affinity for dsDNA with binding constants that are orders of magnitude larger than other DNA binding agents such as intercalating agents (for more on intercalation, see UNIT 8.1). Interactions of MBs with dsDNA have been reviewed (Zimmer and Wahnert, 1986), and the biological activity of anticancer MB compounds has been described in detail (Cory, 1995). Recently, various types of MBs have been attached to synthetic oligodeoxynucleotides (ODNs). Interactions of these MBODN conjugates with DNA have been studied and are reviewed here. Applications of fluorogenic MB-ODNs in quantitative PCR assays are also presented.

MB small molecules have DNA sequence preferences, with A/T-rich dsDNA sequences being especially good targets for binding (Zimmer and Wahnert, 1986). Recently, MBs have been developed that have improved sequence recognition through a dimer-binding motif in which two linked MBs occupy the same binding site (Kielkopf et al., 1998). Sequence-selective interactions between alkylating $\mathrm{MB}$ natural products (analogs of the antibiotic CC1065) and dsDNA have also been reviewed (Boger et al., 1997). These highly toxic molecules react rapidly with $\mathrm{N} 3$ of adenine residues in dsDNA when bound to certain sequences. Other natural products and synthetic MB analogs are even more potent. The high binding strength of the MBs to dsDNA $\left(K_{\mathrm{a}} \sim 1 \times 10^{7}\right.$ to $1 \times 10^{9}$ ) can make them effective "DNA delivery agents" that target specific molecular functions such as DNA-cleaving agents (Boger and Zhou, 1993) or alkylating agents (Inga et al., 1999) to the minor groove of DNA. The conjugation chemistry of distamycin-type MBs has been reviewed (Bailly and Chaires, 1998).

The authors, as well as others, have studied the hybridization performance of MB-ODN conjugates. Short pieces of synthetic DNA with attached MBs have enhanced DNA affinity, and have improved the hybridization properties of sequence-specific DNA probes. Short MBODNs hybridize with single-stranded DNA (ssDNA) strands to give more stable DNA duplexes than unmodified ODNs with similar lengths. Mismatch discrimination of short MBODNs is enhanced in comparison to longer unmodified ODNs. The stronger binding of MB-ODNs allows for more stringent hybridization conditions to be used in DNA probebased assays. MB-ODNs are especially useful in quantitative "real-time" PCR assays since they bind efficiently during the high-temperature primer extension cycle.

The synthesis and biophysical chemistry of MB-ODN conjugates are reviewed here. Four published structural classes of MB-ODNs and their various dsDNA binding modes are discussed. The well-characterized $\mathrm{DPI}_{3}$-type MBODNs and their interactions with ssDNA target strands are described in detail. First, general methods of synthesis of $\mathrm{DPI}_{3}$-ODNs are presented. Next, hybridization properties, mismatch discrimination, and predictability of binding of these conjugates are described. Finally, synthesis and applications of fluorogenic $\mathrm{DPI}_{3}$-ODNs in quantitative PCR assays are discussed.

\section{DNA BINDING MODES AND STRUCTURE OF MB-ODN CONJUGATES}

\section{Binding Modes of MB-ODNs}

MB-ODN conjugates have three distinctive molecular components that can be altered to give sequence-specific DNA probes: the MB, ODN, and linker (Fig. 8.4.2). By varying the MB component, dsDNA binding affinity can be tuned. Altering the length and type of repeat- 


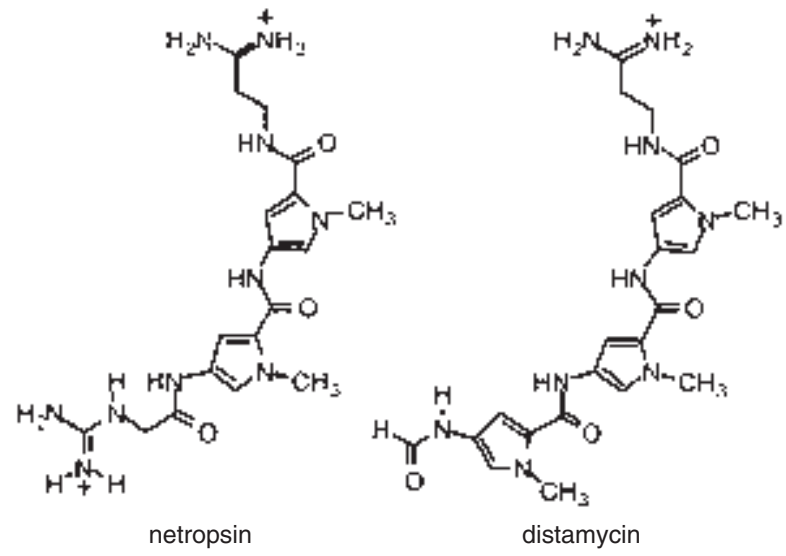<smiles></smiles>

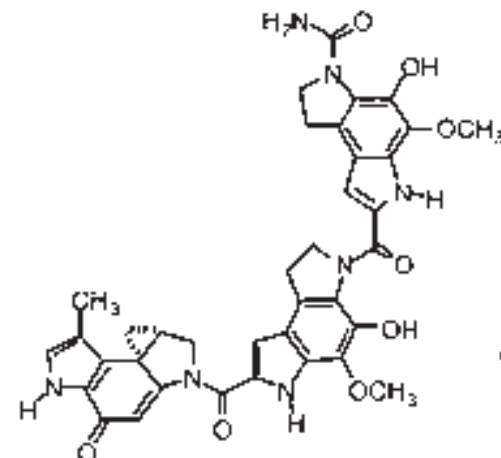

CC-1065

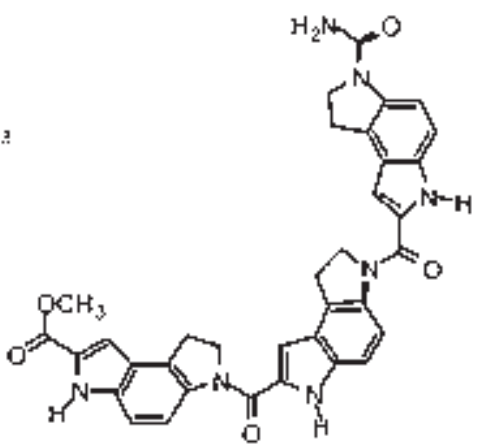

$\mathrm{CDPI}_{3}$ methyl ester<smiles>C[14C]1CCN(c2ccc3nc(-c4ccc5nc(-c6ccc(O)cc6)[nH]c5c4)[nH]c3c2)CC1</smiles>

Hoechst 33258<smiles></smiles>

Chemistry of Minor Groove

Binder-

Oligonucleotide

Conjugates

Figure 8.4.1 Examples of minor groove binders (MBs). The planar, aromatic MB molecular structures are drawn in the presumed crescent shape conformation that binds to DNA duplexes. The inner (concave) edge of each MB faces the minor groove in B-form DNA duplexes. Netropsin, distamycin, and imidazole-lexitropsin are of the distamycin type; CC-1065 is an alkylating CPI type; $\mathrm{CDPI}_{3}$ methyl ester is of the DPI type; Hoechst 33258 represents the Hoechst type; and ImPyPy$\gamma$-PyPyPy-Dp is of the dimer-forming type. See text for a description of each type of MB. 


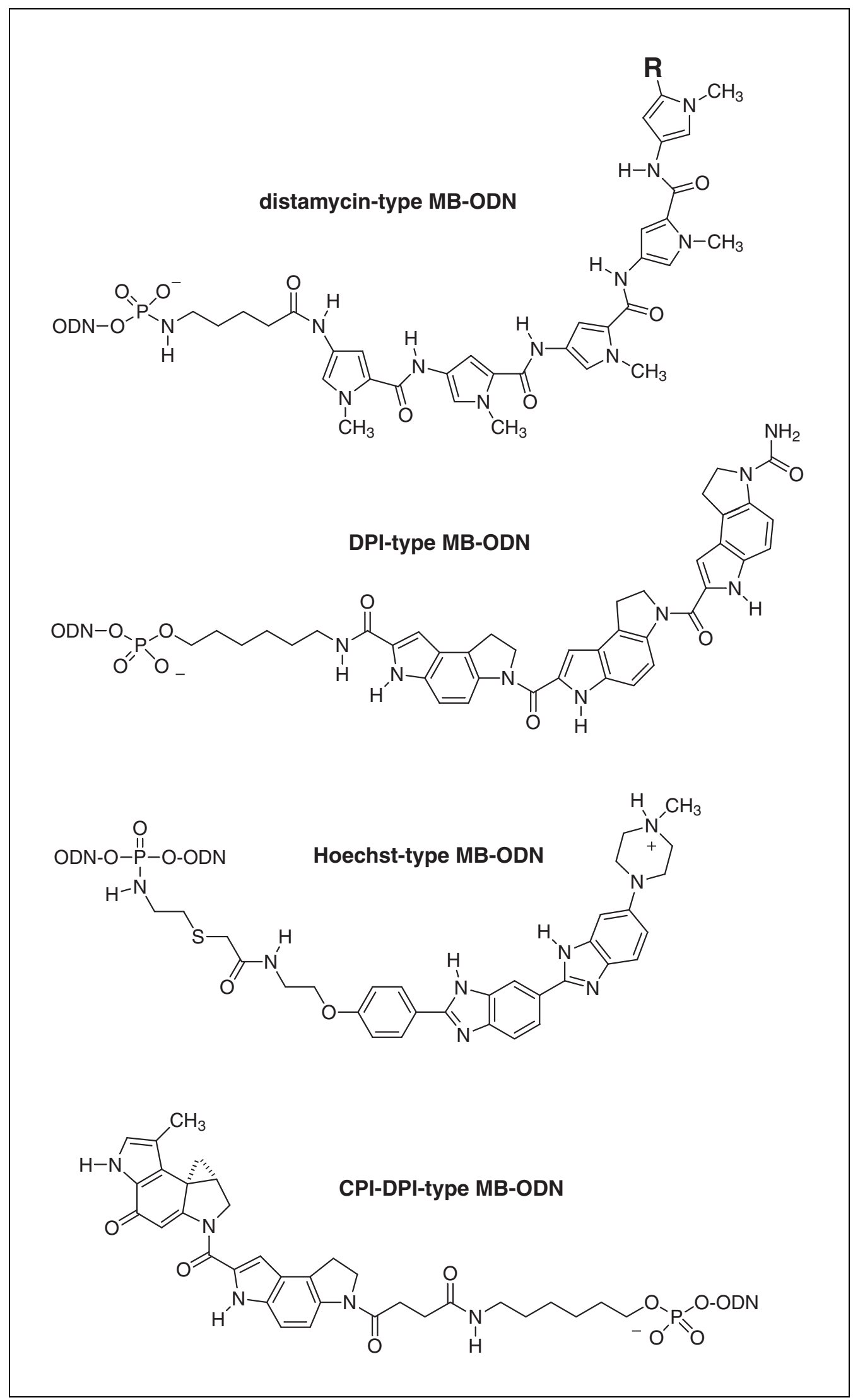

Figure 8.4.2 Published examples of different types of MB-ODN structures. Structures of the MB, the ODN, and the linker all affect hybridization performance. MB-ODN conjugates were prepared by treating an ODN containing a linking group with a suitable reactive group on the MB. The different linker structures are described in the text. R, dabcyl chromophore.

Nucleic Acid Binding Molecules

\subsection{3}

Supplement 13 

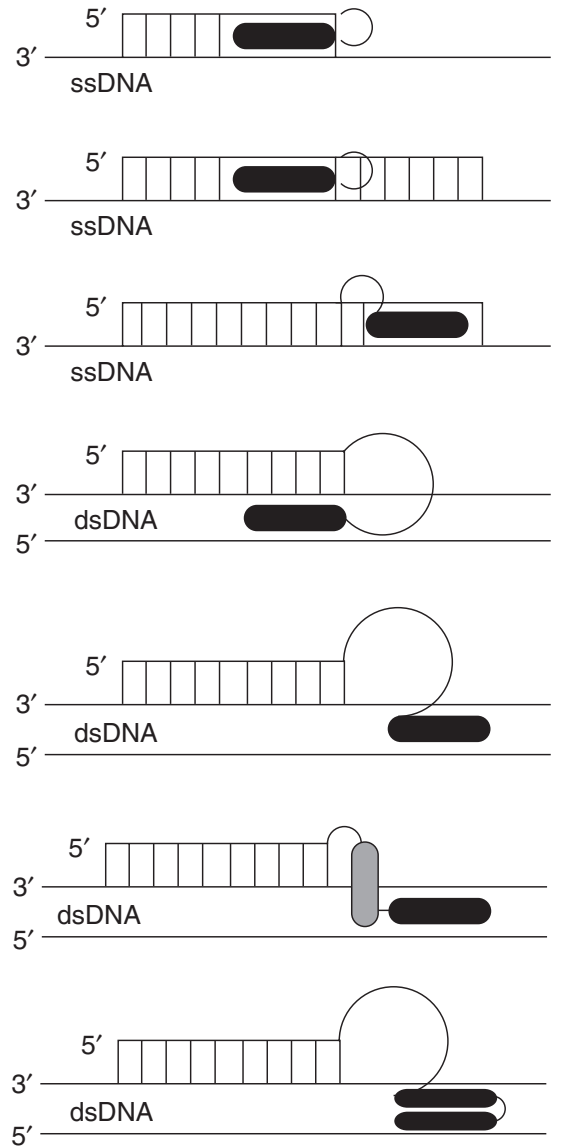

mode 1 : terminal MB

duplex, 5'-folding

mode $2 \mathrm{~A}$ : internal $\mathrm{MB}$ duplex, 5'-folding

mode 2B: internal MB

duplex, 3'-folding

mode 3A: terminal MB

triplex, 5'-folding

mode 3B: terminal MB triplex, 3'-folding

mode 4: terminal MB

triplex, intercalating linker

mode 5: terminal MB

triplex, linked MB dimers
Chemistry of Minor Groove

Binder-

Oligonucleotide

Conjugates

8.4.4

Figure 8.4.3 DNA binding modes of MB-ODNs. The drawings illustrate "unwound" DNA helices with 10-mer MB-ODNs. Mode 1 has the most predictable properties since the MB can only fold into a single dsDNA binding site after hybridization. The outer (convex) edge of the MB is shown as a black oval covering $\sim 5 \mathrm{bp}$ in the minor groove. Longer linkers are required for the triplex binding modes since the ODN is bound in the major groove.

ing subunits in the MB allows the balance between DNA affinity and sequence specificity to be optimized. The ODN component of MBODNs provides sequence-specific interactions with dsDNA via natural Watson-Crick hydrogen bonding. Since most MBs bind more tightly to A/T-rich sites, the base content of the ODN can affect MB binding after hybridization. The position of MB attachment and the length and type of linker combine to confine the $\mathrm{MB}$ to various local regions of dsDNA. MB-ODNs can recognize dsDNA in a variety of binding modes as illustrated in Figure 8.4.3 and discussed below. In addition to simple DNA duplex formation with ssDNA targets, MB-ODNs have been used to improve binding of triplex-forming oligonucleotides (TFOs). The different binding modes of MB-ODNs have different linker requirements, and each linker must be properly designed for optimum performance. Understanding the effects of the MB on DNA hybridization allows DNA probe performance to be predicted as described below.

\section{Terminal MBs and ssDNA targets (binding mode 1)}

In binding mode $1, \mathrm{MB}-\mathrm{ODN}$ form DNA duplexes and the MB linked to the terminus folds into the newly formed minor groove. In Figure 8.4.3, a $3^{\prime}$-linked MB is illustrated, but the binding mechanisms are analogous for $5^{\prime}$ linked MBs. The linker needs to be long enough to allow the MB to orient itself in the groove, but not so long that it can find other DNA binding sites. This is an important issue since predictable duplex stability requires the MB binding site to be known. Binding mode 1 
allows predictable hybridization properties for DNA probe applications, and is described in detail for the terminally modified $\mathrm{DPI}_{3}$-type MB-ODNs (see Synthesis and Hybridization of $\mathrm{DPI}_{3}$-Type MB-ODNs and Fig. 8.4.2).

\section{Internal MBs and ssDNA targets (binding mode 2)}

This binding mode was explored with the Hoechst-type MBs and involves internal linkers to the ODN (Fig. 8.4.3; Wiederholt et al., 1996, 1997). This mode is complicated by the ability of the MB to find one of two possible binding sites - towards either the $5^{\prime}$ terminus (mode $2 \mathrm{~A}$ ) or the $3^{\prime}$ terminus (mode $2 \mathrm{~B}$ ) of the hybridized MB-ODN. This made binding to ssDNA targets unpredictable since the "twostate" model (equilibrium of ssDNA and dsDNA) no longer operates. In addition, the internal linkage via a phosphoramidate bond introduced stereoisomers that had specific directional effects for the various isomers. Despite this complexity, certain internally modified MB-ODNs could form strong duplexes with appropriate ssDNA targets. Fluorescent signal correlated well with dsDNA stability, but the unpredictable nature of these probes and the complexity of the synthesis made MB-ODNs that operate via mode 2 less attractive.

\section{Terminal MB linkers and dsDNA targets (binding mode 3)}

Triplex-forming oligonucleotides (TFOs) recognize and bind to homopurine sequences in the major groove of dsDNA (Thuong and Helene, 1993). As a result, the terminal MB must be attached to a linker that is long enough to reach around the sugar-phosphate backbone to the minor groove of the dsDNA target. The triplex-stabilizing binding modes are illustrated as mode 3 in Figure 8.4.3. MBs conjugated to TFOs have been shown to improve binding affinity to dsDNA (Robles et al., 1996; Rajur et al., 1997; Robles and McLaughlin, 1997). These MB-ODN conjugates used the Hoechst-type MBs. The various long linkers studied allowed the MB in triplexes to either fold back towards itself (mode 3A) or extend out toward the neighboring duplex region (mode 3B).

Alkylating CPI-type analogs of MBs have also been conjugated to TFOs (Lukhtanov et al., 1997), and their interaction with dsDNA has been explored. As much as $98 \%$ targeted alkylation of dsDNA was observed for optimized linkers. Addition of a DPI subunit (see Fig. 8.4.2) was required for this high DNA alkylation efficiency with triplex targeting. Unfortunately, this CPI-DPI conjugate gave high nonspecific binding and alkylation of the DNA. Non-TFO-directed binding is a general problem with the triplex-directed MBs.

\section{Other MB binding modes}

Other MB binding modes have also been explored with TFOs. In order to prevent nonspecific binding of alkylating CPI-type MBs, a novel "threading intercalator" linker was developed (Dempcy et al., 1999). In this motif, the CPI was delivered to the minor groove by threading through the helix, presumably after triplex binding (mode 4; Fig. 8.4.3). Sequencespecific DNA alkylation of up to $88 \%$ was observed on synthetic targets. The strongest intercalating linker showed some nonspecific alkylation.

Another MB binding motif has been described for TFOs conjugated with dimer-forming MBs synthesized from mixed pyrrole and imidazole heterocycles (Kielkopf et al., 1998). After triplex formation, the sequence-specific MB dimers targeted mixed-base stretches adjacent to the TFO sequence (mode 5; Fig. 8.4.3). In one example (Szewczyk et al., 1996a), two TFOs were required where one of the MB dimers was at the $3^{\prime}$ end of one TFO and the other was at the $5^{\prime}$ end of the adjacent TFO. The MBs could interact only after both TFOs hybridized. In theory, this could improve sequence specificity of triplex-forming MBODNs. The mode has severe sequence limitations, and requires design and synthesis of $\mathrm{MB}$ dimers for targeted delivery to each dsDNA sequence of interest. In another example (Szewczyk et al., 1996b), a linked MB dimer was directly conjugated to a TFO and allowed each sequence-specific element to interact separately. A matching set of MB dimers must be prepared for optimum binding to each specific DNA sequence, and suitable chemistry has been described (Baird and Dervan, 1996). The threading intercalators and dimer-type MBs are not described further in this unit.

\section{Types of MB-ODNs}

Numerous types of MBs are available for conjugation to synthetic ODNs, and the specific molecular interactions responsible for dsDNA binding vary. MB conjugate synthesis requires a reactive linking group on the $\mathrm{MB}$. This requires synthetic organic chemistry to develop the "conjugatable" MBs. The MB linking group then reacts with another linking group on the oligonucleotide. These linking
Nucleic Acid Binding Molecules

8.4.5

Supplement 13 
groups are readily introduced during DNA synthesis. Structural designs of several published MB-ODN conjugates are shown in Figure 8.4.2. The most notable structural similarity between the MBs is their ability to form stable crescent-shaped conformations in aqueous solution that can fit snugly in the minor groove of B-form DNA. However, each type of MBODN has unique physical properties and chemistry. Investigators chose the MBs shown in Figures 8.4.1 and 8.4.2 because the synthetic chemistry had been developed and the binding mechanisms had been studied. The distamycintype and Hoechst-type MBs have oriented heteroatom-bonded protons on the inside of the crescent-shaped structures that allow hydrogen bonds to form with functional groups on the floor of the minor groove. The $\mathrm{DPI}_{3}$-type MBs are more hydrophobic and bind to the minor groove mostly because of differences in the energies of MB-DNA and MB-water interactions (that is, reduction of MB-water "interface" and surface tension; Mikheikin et al., 2001).

Synthesis of the MB-ODN conjugates can be complicated, but has been improved significantly as discussed below. Structural analogs of MB-ODNs with various types of MBs, attachment points (internal versus terminal), and linker structures have been explored. The effect of MB and linker lengths on biophysical properties of these classes of MB-ODN conjugates is described below. The distamycin and $\mathrm{DPI}_{3}$ conjugates are noteworthy since the repeating subunits can be prepared from common heterocyclic precursors, and assembled using welldeveloped peptide chemistry. This simplified the synthesis of these complex biomolecules, and allowed MB analogs of various lengths (DNA affinity) to be studied. The synthesis and hybridization properties of the $\mathrm{DPI}_{3}$ conjugates are described in detail in later sections.

\section{Distamycin-type MBs}

The first MB-ODN conjugates described in the literature were the distamycin type (Sinyakov et al., 1995). Distamycin and netropsin are naturally occurring antibiotics that contain repeating subunits of $\mathrm{N}$-methylpyrrolecarboxamide (MPC). Distamycin has three repeating MPC subunits whereas netropsin has two MPC subunits (Fig. 8.4.1). The top structure in Figure 8.4.2 is an example of a distamycin-type MBODN with five MPC subunits. Both distamycin and netropsin also contain a positively charged amidine group that aids water solubility and provides additional DNA affinity. The synthetic chemistry for preparing and linking the MPC subunits had been developed earlier, and the stepwise peptide coupling chemistry allowed ready access to MPC peptides of various lengths. A reactive alkylamine linker arm at the $\mathrm{N}$-terminus of the peptide was introduced for conjugation to ODNs. Similar conjugation chemistry was later used to directly attach netropsin and distamycin to ODNs (Levina et al., 1996).

UV melting measurements of DNA duplexes formed with $\mathrm{T}_{8}$-MB-ODNs and complementary ssDNA strands (binding mode 1) showed dramatic increases in melting temperature $\left(T_{\mathrm{m}}\right)$. The MB-ODN conjugates were well behaved in standard physiological buffer conditions. Melting curves showed good cooperativity, typical of unmodified DNA strand melting. The results of these studies are shown in Figure 8.4.4A. The first derivatives of the melting curves showed a stepwise increase in $T_{\mathrm{m}}$ as the number of MPC subunits increased from two to five. MB-ODN conjugates with five repeating MPC subunits showed an increase in $T_{\mathrm{m}}$ of $44^{\circ} \mathrm{C}$ in comparison to an unmodified DNA duplex. In comparison, conjugation of distamycin-type MBs to a G/C-rich 8-mer ODN gave no significant increase in duplex stability as shown in Figure 8.4.4B.

Conjugation of the hydrophobic distamycin-type MBs to ODNs improved the water solubility of the MB significantly and allowed hybridization to occur in standard aqueous buffers. This is a significant advantage, since many MBs are sparingly soluble in water and conjugation to ODNs allows their exploration as DNA-targeting agents. For example, the stabilization of unconjugated MPC molecules could not be studied due to insolubility. In addition, the local concentration of hydrophobic MBs at the attachment point to the ODN is much higher than can be achieved by adding free MB to DNA duplexes in solution. Although hydrophobic MBs initially complicated the conjugation to hydrophilic ODNs, a broader range of potential MB structures could ultimately be explored.

Although no direct evidence was presented that showed minor groove binding of the distamycin-type MB-ODN conjugates, the A/T specificity of the stabilization and the stepwise increase in $T_{\mathrm{m}}$ with MB length was compelling. Also consistent with an MB mechanism was the relative lack of affinity to RNA of the distamycin-type MB-ODNs. Presumably, the mechanism of binding first involves duplex formation of the MB-ODN with its comple- 
mentary strand. The conjugated MB can then fold back into the newly created minor groove where it is stabilized by hydrophobic interactions. For the distamycin-type MBs, additional stability is provided by hydrogen bonds from the amide hydrogens to $\mathrm{N} 3$ of adenine or $\mathrm{O} 2$ of thymine. Lack of stabilization of G/C-rich sequences is presumably due to the steric hindrance and relative hydrophilicity provided by the N2 of guanine. Lack of binding to RNA is presumably due to the wide, shallow minor groove in the A-form duplexes of DNA/RNA hybrids. This is typical of distamycin-type MBs.

\section{DPI-type MBs}

The natural product CC-1065 is an alkylating $\mathrm{MB}$ with potent antibiotic activity. Certain
A/T-rich sequences are efficiently alkylated, and much is known about the sequence-specific binding (and bonding) mechanisms involved (Boger and Johnson, 1995). The structure of CC-1065 has a repeating 1,2-dihydro-3H-pyrrolo[3,2-e]indole-carboxylate (DPI) subunit that provides dsDNA affinity. The alkylating cyclopropapyrroloindole (CPI) subunit of CC1065 can react with A3 of adenine in B-form DNA, and provides the structural basis of the CPI-type MB-ODNs (see CPI-type MBs below). DPI dimers, trimers, and tetramers were prepared as high-affinity, noncovalent B-DNA minor groove-binding agents (Boger et al., 1987). Unlike the distamycin-type MBs, the angular tricyclic structure of the DPI subunit pre-organizes these MBs to form crescentshaped conformations that are isosteric with the

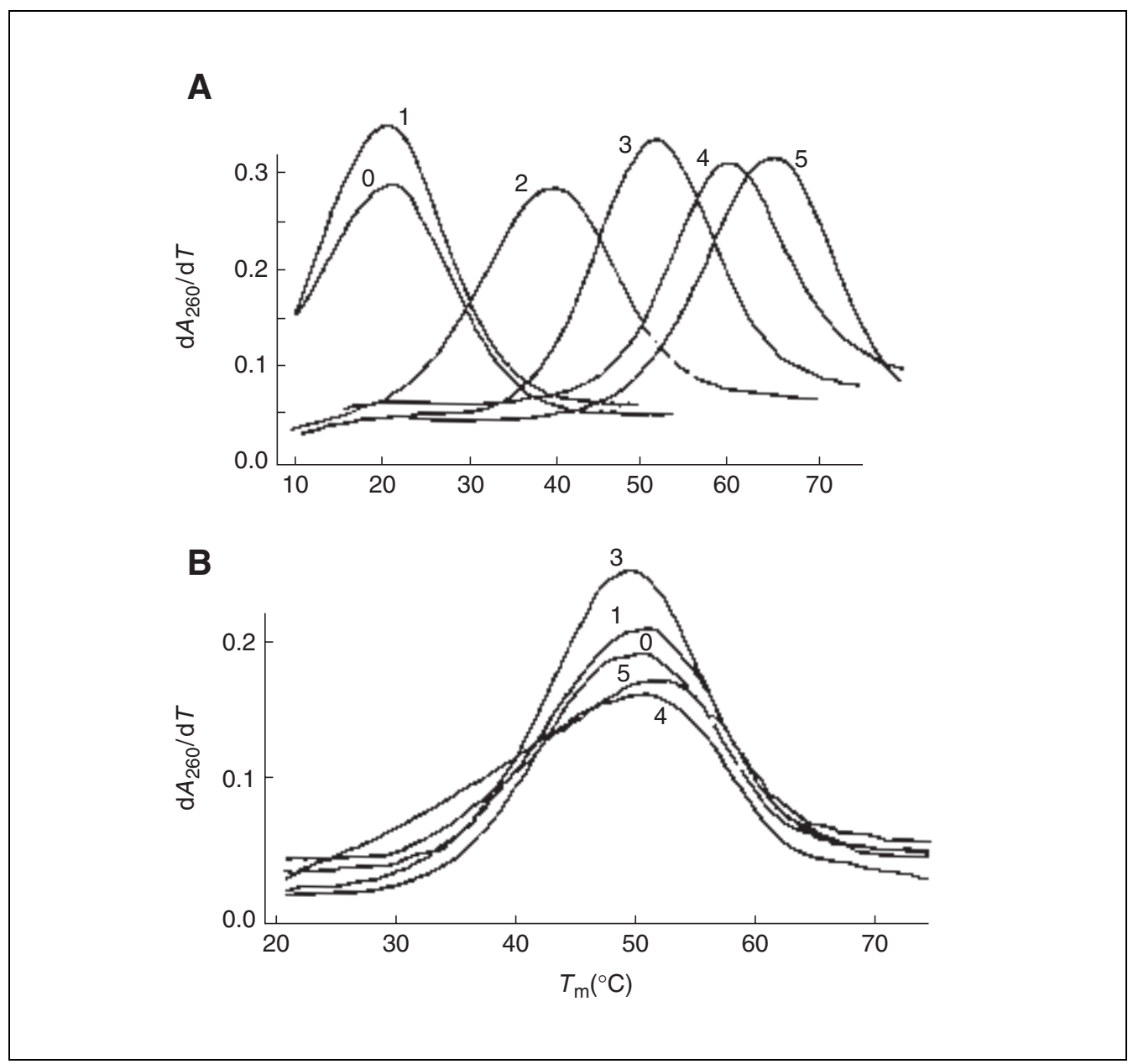

Figure 8.4.4 UV melting curves of DNA duplexes formed from distamycin-type MB-ODNs and their complements. First derivative plots of helix-coil transitions at $260 \mathrm{~nm}$ for 3'-MB-ODN duplexes are shown. Distamycin-type MBs of various lengths were prepared with zero to five MPC subunits and conjugated to $\mathrm{dT}_{8}$ or G/C-rich 8-mer ODNs. (A) TTTTTTTT-MPC ${ }_{n}(n=0$ to 5). (B) CATCCGCT$\mathrm{MPC}_{n}(n=0,1,3,4,5)$. The A/T-rich duplex shows a stepwise increase in duplex melting termperature $\left(T_{\mathrm{m}}\right)$ with increasing MB length, whereas the G/C-rich duplex shows no increase in stability. Reprinted from Sinyakov et al. (1995) with permission from the American Chemical Society.

Nucleic Acid Binding Molecules

\subsection{7}

Supplement 13 
minor groove of B-form DNA. The well-developed synthetic chemistry of the DPI-type MBs allowed exploration of their ODN conjugates soon after the distamycin-type MB-ODNs (Lukhtanov et al., 1995). Conjugation methods were developed (see below) that simplified the synthesis of DPI conjugates in comparison to the distamycin type, and this allowed a variety of analogs to be examined. Most of these early DPI analogs retained the $\mathrm{N}$-terminal carbamoyl group and were abbreviated as CDPI. It was later shown (Lukhtanov et al., 1996a) that the carbamoyl group was not necessary, and other linker groups could be added at this position. The synthesis and properties of the DPI-type MB-ODNs are described in detail below. The major advantage of the DPI-type MBs is the lack of hydrogen bonding groups in the inner surface of the crescent-shaped conformation. DNA duplex stabilization by DPI-type MBs is primarily due to close atomic contacts (van der Waals forces). The importance of hydrophobic interactions and van der Waals forces (Chang and Cheng, 1996) in the DPI-type MBs has been discussed (Boger et al., 1990). Unlike the distamycin-type MBs, the DPI-type MBs can significantly stabilize G/C-rich duplexes. In addition, the lack of hydrogen bonding in the minor groove makes hybridization properties of DPI-type MBs more predictable.

\section{Hoechst-type MBs}

The Hoechst-type MBs are based on a benzimidazole dye structure with interesting biophysical properties (Hoechst 33258; Fig. 8.4.1). This compound is known to prefer $\mathrm{A} / \mathrm{T}$ rich binding sites in dsDNA, but analogs have been prepared that show some $\mathrm{G} / \mathrm{C}$ tolerance (Singh et al., 1992). The compounds are moderately fluorescent in aqueous solutions, but quantum yield increases some 20 -fold in the presence of dsDNA. The DNA binding and fluorogenic properties of the Hoechst-type MBs made them interesting candidates for targeted delivery by ODNs. Enhanced stability was first explored by preparing TFOs with tethered Hoechst-type MBs (Robles et al., 1996; Robles and McLaughlin, 1997). As described above for binding mode 3 , a long linker between the MB and ODN is a critical component for the TFO binding mode to be successful. An 18-atom hexa(ethylene glycol) linker was used, and the resulting three-stranded complex showed increased stability ( $T_{\mathrm{m}}$ values of the triplexes increased by as much as $\left.18^{\circ} \mathrm{C}\right)$. In addition, these three-stranded complexes showed increased fluorescence, consistent with minor groove binding.

Duplex-stabilizing effects with internally linked Hoechst-type MB-ODNs were also explored (Wiederholt et al., 1996, 1997). As described above for binding mode 2, this approach allows several potential types of complexes to be formed. The linker structure of the internal modification is shown in Figure 8.4.2. The ODN conjugates were formed by first introducing a protected thiol linker at an internal phosphate through a phosphoramidate bond. This introduced two stereoisomers at this position that influence the direction in which the $\mathrm{MB}$ is oriented (towards the major or minor groove). The MB-ODN was prepared by reacting the thiol with a bromoacetyl derivative of the Hoechst-type MB. Despite difficulties described for isolation, enough conjugate was isolated to study the hybridization properties. These internal MB-ODNs showed increased duplex stability, with dramatic differences between the stereoisomers (increased $T_{\mathrm{m}}$ values of $6^{\circ} \mathrm{C}$ versus $18^{\circ} \mathrm{C}$ ). Increased fluorescence upon hybridization was consistent with these increases in MB binding efficiency.

Finally, duplex-stabilizing effects with terminally linked Hoechst-type MB-ODNs were explored (binding mode 1). The same 18-atom hexa(ethylene glycol) linker that was developed for triplex targeting was used for the duplex system (Rajur et al., 1997). Introduction of the tethered MB to the $5^{\prime}$ terminus of the ODN was accomplished by forming a $5^{\prime}$-phosphoramidite on the protected ODN after DNA synthesis. This was treated with the alcohol form of the linker-MB, and the conjugate was deprotected with ammonia as usual. This resulted in better yields of Hoechst-type MBODNs, and allowed various duplex systems to be studied. As expected, increases in duplex stability were observed. The $T_{\mathrm{m}}$ increased as much as $14^{\circ} \mathrm{C}$ for $\mathrm{A} / \mathrm{T}$-rich 15 -mer sequences. There was little increase in binding to $\mathrm{G} / \mathrm{C}$-rich targets. The differences in $T_{\mathrm{m}}$ corresponded to differences in fluorescence (higher $T_{\mathrm{m}}$ gave greater fluorescence). It was noted that the long linker allowed the MB to reach A/T-rich binding sites far removed from the terminus. A shorter tri(ethylene glycol) linker allowed the tethered MB to reach binding sites four bases removed from the end of the duplex. As described above, this can improve binding affinity for some sequences, but the stabilization is unpredictable.
Chemistry of Minor Groove BinderOligonucleotide Conjugates 8.4.8 


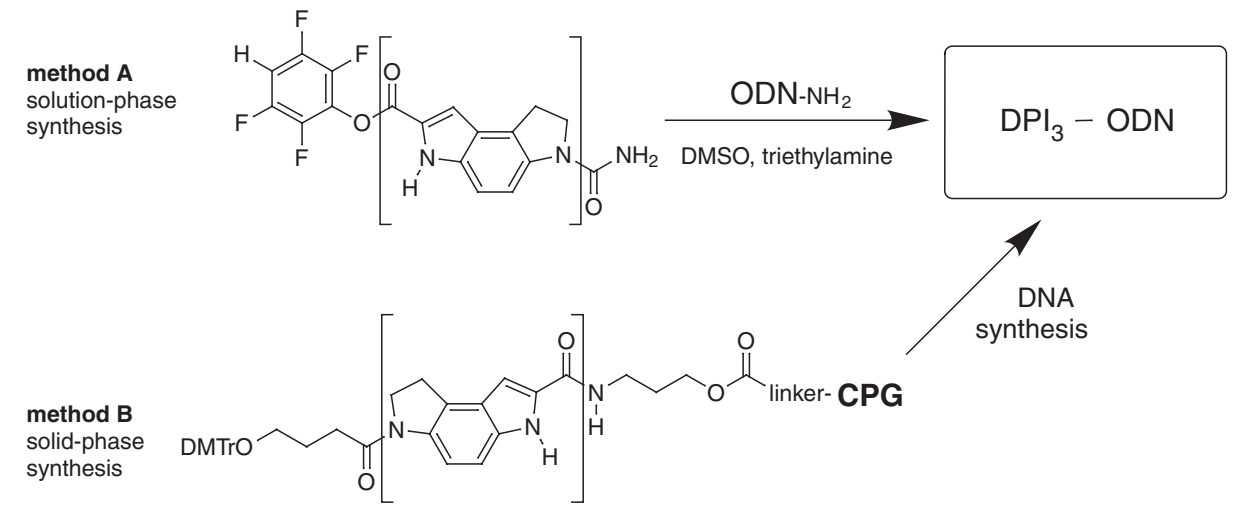

Figure 8.4.5 Synthesis methods for $\mathrm{DPI}_{3}$-type $\mathrm{MB}-\mathrm{ODNs}$. Method $\mathrm{A}$ involves acylation of aminemodified ODNs using $\mathrm{DPI}_{3}$-activated esters. Method $\mathrm{B}$ uses $\mathrm{DPI}_{3}$-modified glass beads that allow rapid synthesis of MB-ODNs with only slight modification of standard automated DNA synthesis methods. $\mathrm{DPI}_{3}$-ODNs are easily purified by reversed-phase HPLC methods. Both $5^{\prime}$ - and $3^{\prime}$-labeled conjugates can be synthesized from the same CPG reagent by using the appropriate $5^{\prime}$ or $3^{\prime}$ phosphoramidite nucleoside bases. CPG, controlled-pore glass; DMSO, dimethyl sulfoxide; DMTr, 4,4'-dimethoxytrityl.

\section{CPI-type MBs}

As described for binding mode 3, MBs containing the alkylating subunit of CC-1065 have been used to site-specifically alkylate certain DNA sequences. It is amazing that nature evolved molecular machinery that could create such efficient dsDNA-targeting molecules. The left-hand subunit of the CPI-DPI-type MBODN in Figure 8.4.2 contains a hybridizationtriggered cyclopropyl functional group that can alkylate N3 of adenine in dsDNA. A single "conjugatable" CPI subunit was developed, ODN conjugates were prepared, and ssDNA targets were alkylated with the simple CPI subunit (Lukhtanov et al., 1996b). In a later report, a detailed analysis of the kinetics of alkylation of ssDNA and targets showed the sequence specificity of various CPI and CPIDPI analogs (Lukhtanov et al., 1997). Triplex binding and alkylation with CPI-type MBODNs required the additional DPI subunit (see Fig. 8.4.2) for efficient alkylation (Lukhtanov et al., 1997). The CPI-type MBs are more aptly described as minor groove "bonding" agents, and are not discussed further in this unit.

\section{SYNTHESIS AND HYBRIDIZATION OF DPI3-TYPE MB-ODNs}

\section{Conjugation Chemistry}

As described earlier, conjugation of the MPC peptides to short ODNs presented technical hurdles (Sinyakov et al., 1995). MPC derivatives containing an aminohexanoyl linker were prepared with one to five MPC subunits. Conjugation was accomplished by activating a $3^{\prime}$ phosphate on $\mathrm{A}_{8}, \mathrm{~T}_{8}$, or mixedsequence 8-mer ODNs in organic solvents and utilized the organic-soluble cetyltrimethylammonium (CTAB) salts of the ODNs. Since the simple MPC analogs lacked the positively charged amidine group present in distamycin, organic solvent (dimethylformamide) was required to dissolve the hydrophobic MPC derivatives. Preparation and handling of the CTAB salts was not described in detail, but isolated yields of $30 \%$ to $50 \%$ were reported. Despite the complexity of synthesis, distamycin-type MB-ODN conjugates were isolated as pure organic compounds. Purification of the conjugates was aided by a dabcyl chromophore ( $\mathrm{R}$ group in Fig. 8.4.2) that was present on the C-terminal MPC subunit.

Preparation of DPI-activated esters (Lukhtanov et al., 1995) allowed easy access to the convenient conjugation methods shown in Figure 8.4.5. The simple formation of amide
Nucleic Acid Binding Molecules

8.4.9

Supplement 13 


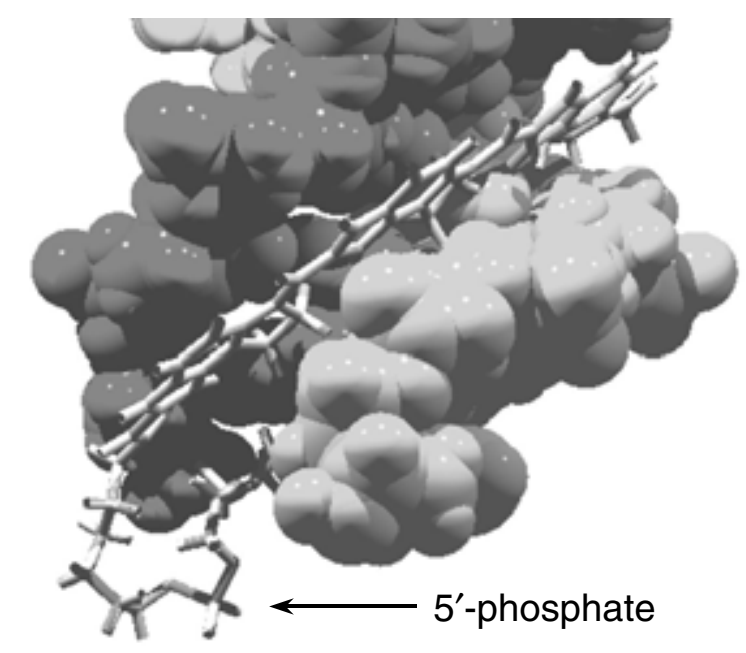

Figure 8.4.6 Solution structure of the minor groove binding site in a $\mathrm{DPl}_{3}$-ODN/DNA duplex was determined by NMR. The rendering above shows the $5^{\prime}-\mathrm{DPI}_{3}$, the linker structure, and the terminal T-A base pair as solid bonds in a space-filling DNA duplex. The $\mathrm{DPI}_{3}$ covers 5 to $6 \mathrm{bp}$ in the minor groove. A $5^{\prime}$-DPI ${ }_{3}$-ODN with sequence $5^{\prime}$-TGATTATCTG was made by method A (Fig. 8.4.5) and hybridized to a complementary DNA strand. The $\mathrm{DPI}_{3}-\mathrm{ODN} / \mathrm{DNA}$ duplex had the same B-form conformation as an unmodified 10-mer DNA duplex (Kumar et al., 1998). The atomic coordinates for this structure were deposited in the Protein Data Bank as PDB ID: 1AUL.

bonds in organic solvents was easily adapted to synthesis of ODN conjugates since an aminohexyl linker arm can be conveniently added to either end of the strand during DNA synthesis. The linked DPI subunits have strong UV absorbance at $\sim 340 \mathrm{~nm}$, which simplifies analysis of the conjugation chemistry and aids in characterization of the DPI-type MB-ODNs. The DPI-type MBs are more hydrophobic than the distamycin-type $\mathrm{MBs}$, and reversed-phase HPLC is a convenient method for analysis and purification of DPI-type MB-ODNs.

Conjugation method A used solution-phase conjugation chemistry (in organic solvents). The described method (Lukhtanov et al., 1995) still required that $\mathrm{CTAB}$ salts of the ODN be prepared, but formation of amide bonds by reacting the $\mathrm{DPI}_{3}$-activated ester with aminohexyl-modified ODNs was simpler than the distamycin-type MB conjugation chemistry. The solution-phase conjugation chemistry was improved significantly when it was found that triethylammonium (TEA) salts of ODNs are soluble in anhydrous dimethyl sulfoxide (DMSO; Milesi et al., 1999). The purified TEA salts of ODNs are easily isolated by reversedphase HPLC, dried in vacuo, and treated directly with activated esters. The method was described in detail for preparation of $\mathrm{DPI}_{3}-$
ODNs. This acylation method couples HPLCpurified aminohexyl-ODNs with $\mathrm{DPI}_{3} \mathrm{TFP}$ (tetrafluorophenyl) or PFP (pentafluorophenyl) ester to give the HPLC-purified $\mathrm{DPI}_{3}-$ ODN as a single, well-resolved peak.

Conjugation method B describes DNA synthesis directly from $\mathrm{DPI}_{3}$-modified controlledpore glass (CPG) supports. This method is the most versatile if many different $\mathrm{DPI}_{3}-\mathrm{ODN}$ sequences are required, since each synthesis is performed in a separate column and can be easily automated. A flexible aminodiol linker allows simultaneous attachment of the MB to a dimethoxytrityl (DMTr)-protected hydroxyl group that forms the starting point for DNA synthesis. If standard phosphoramidite chemistry is used, $3^{\prime}$-DPI ${ }_{3}$ conjugates can be prepared. If $5^{\prime}-\mathrm{DPI}_{3}$ conjugates are desired, reverse ( $3^{\prime}$-DMTr) phosphoramidites can be used. The $\mathrm{DPI}_{3}$ is able to survive optimized DNA synthesis conditions. For example, iodination of the DPI subunits during the oxidation cycle is a possible side reaction for the $\mathrm{DPI}_{3}-\mathrm{ODNs}$, but can be prevented by using a lower concentration of iodine. It was noted that truncated failure sequences also contain the hydrophobic $\mathrm{DPI}_{3}$, but these side products (and those corresponding to damaged DPI) are easily separated by reversed-phase HPLC purification. Various 
linker structures were used in construction of other $\mathrm{DPI}_{3}$-CPGs. Another method described direct peptide coupling of the DPI subunits on CPG to prepare the $\mathrm{DPI}_{3}$-CPG (Lukhtanov et al., 1996a). Although the method simplified assembly of the DPI-type MBs, excess DPI reagent was required at each peptide coupling step, and quality was more difficult to control.

A related conjugation method involves treatment of the CPG-bound ODN after removal of a 5-monomethoxytrityl (5-MMTr) protecting group from an aminohexyl linker arm (Lukhtanov et al., 1995). This method has the advantage that the heterocyclic bases in the immobilized ODN strands are still protected, and allows the use of organic solvents to introduce the DPI-type acylating agents. The disadvantage of this method is that the $\mathrm{DPI}_{3}$ must be able to survive the harsh ammonia deprotection conditions. Fortunately, the amide bonds in the $\mathrm{DPI}_{3}$-ODNs survive these conditions with little hydrolysis.

In summary, all of the DPI conjugation methods are useful, and selection of a synthetic strategy depends on the scale and desired level of purity. For example, method A proved to be the most efficient for larger-scale synthesis of a $5^{\prime}-\mathrm{DPI}_{3} 10$-mer ODN for NMR studies (Kumar et al., 1998). In this synthesis method, the valuable $\mathrm{DPI}_{3}$ TFP ester was used in only threefold excess, and the $\mathrm{DPI}_{3}$ was not subjected to harsh deprotection or DNA synthesis conditions. The MMTr-on oligonucleotide was purified by HPLC, deprotected, and repurified by HPLC. A yield of $4 \mathrm{mg}$ of the $\mathrm{DPI}_{3}-\mathrm{ODN}$ conjugate was isolated as the sodium salt after precipitation from sodium perchlorate in acetone ( $42 \%$ yield starting from the amine-modified ODN).

\section{Structure of a DPI3-ODN/DNA Duplex}

A 5'-linked $\mathrm{DPI}_{3}$-ODN conjugate with sequence $5^{\prime}$-TGATTATCTG was hybridized to a complementary ODN strand and the solution structure was determined by NMR as shown in Figure 8.4.6 (Kumar et al., 1998). Under suitable aqueous conditions, the complementary DNA strands first assemble by natural WatsonCrick hydrogen bonding to the preferred Bform double helix. The $5^{\prime}$-linked hydrophobic $\mathrm{DPI}_{3}$ explores conformational space (i.e., it swings around) and positions itself in the newly formed (hydrophobic) minor groove. Analysis by NMR showed that the $\mathrm{DPI}_{3}-\mathrm{ODN} / \mathrm{DNA}$ duplex has the same B-form structure as an unmodified 10-mer duplex of the same sequence. The crescent-shaped $\mathrm{DPI}_{3}$ is a "perfect fit" for B-form DNA, and stabilizes the duplex by forming close contacts with both DNA strands in the minor groove. The electron density of the hydrophobic $\mathrm{DPI}_{3}$ is well-contained within the sugar-phosphate "walls" of the minor groove. The NMR structure of the $\mathrm{DPI}_{3^{-}}$ ODN duplex in solution shows the minor groove-binding region covers 5 to $6 \mathrm{bp}$ of the DNA duplex.

As described below, thermodynamic analysis shows that DNA duplex stabilization provided by the conjugated $\mathrm{DPI}_{3}$ molecule is due mainly to an increase in the entropy $(\Delta S)$ of the hydrated duplex system (see Thermodynamics of Hybridization). The minor groove of B-form DNA contains different types of oriented interand intra-strand water bridges (water of hydration; Savage, 1993). Crystallography of highly hydrated B-form DNA duplexes shows a wellordered "spine of hydration" in the minor groove of A/T-rich sites (Dickerson et al., 1982). Although interaction of $\mathrm{DPI}_{3}$ in the minor groove implies a certain degree of unfavorable loss of entropy, the total hydrated system increases in entropy. This entropy compensation is a result of two different entropic factors. First, an increase in entropy accompanies expulsion of the well-ordered water of hydration in the minor groove. A single crescent-shaped $\mathrm{DPI}_{3}$ molecule presumably displaces ten to thirteen organized water molecules in the spine (Dickerson et al., 1982). Second, as mentioned above, the organized water interface around the unbound hydrophobic $\mathrm{DPI}_{3}$ is significantly reduced. After binding, the planar surface area of $\mathrm{DPI}_{3}$ is shielded in the minor groove, and a simplified water layer can form on top of the molecule in the binding region. The NMR structure shows the hydrophobic $\mathrm{DPI}_{3}$ molecule deeply buried within the A/T-rich minor groove. For G/C-rich binding sites, the N2 group of guanine protrudes into the minor groove and prevents the deep binding of $\mathrm{DPI}_{3}$. In that case, the geometry of the water layer over the MB site is more complex, and entropic stabilization of the system is decreased.

\section{HYBRIDIZATION PROPERTIES OF DPI3-ODNs}

\section{DNA Duplex Stabilization}

The dsDNA binding properties of the DPItype MB-ODNs have many similarities to those of distamycin-type MB-ODNs. The UV melting curves of DPI-ODNs in Figure 8.4.7 show the same increase in DNA binding affinity with increasing numbers of DPI subunits shown in
Nucleic Acid Binding Molecules

8.4.11

Supplement 13 


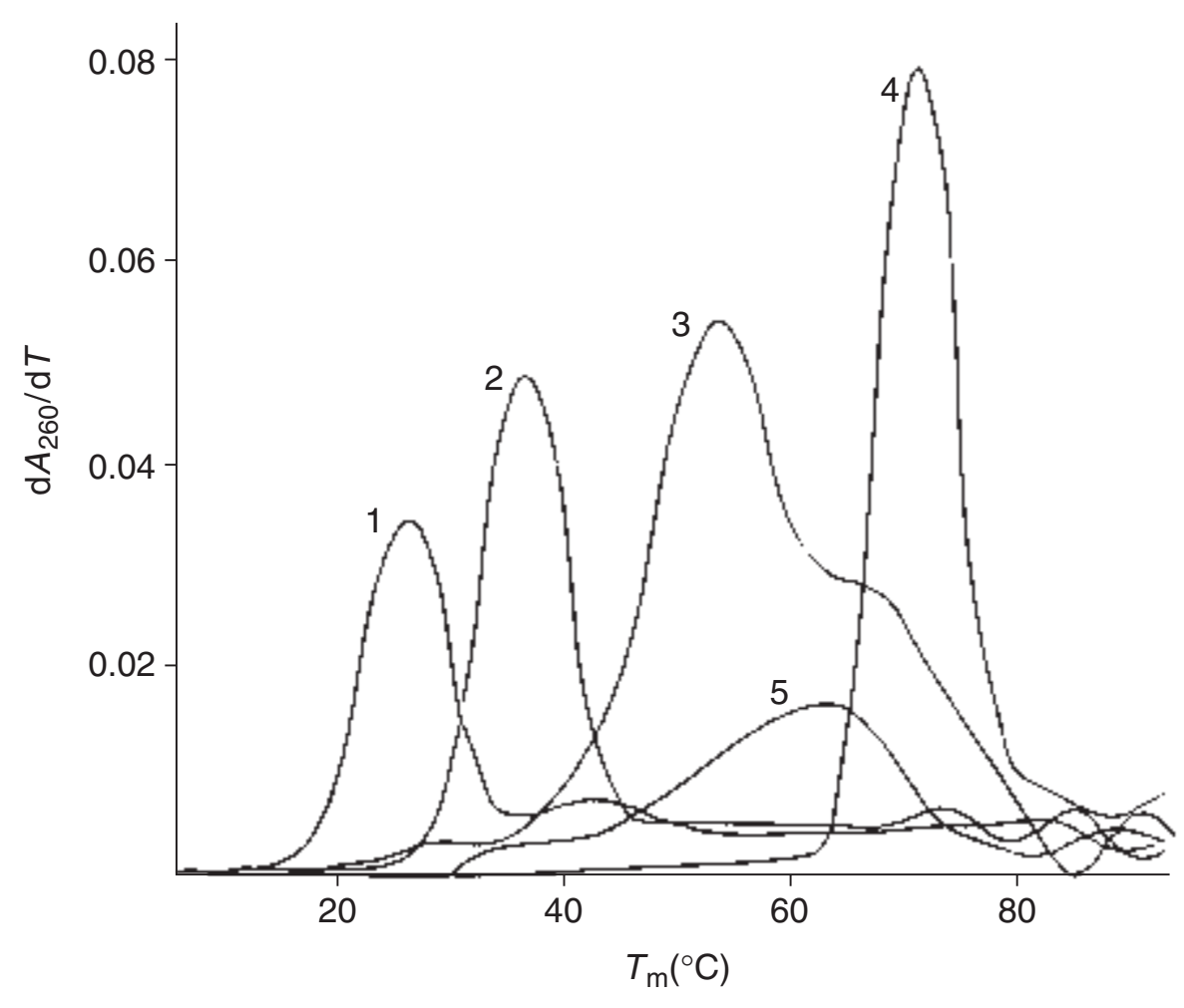

Figure 8.4.7 Differential UV melting curves for complexes formed with DPI-type MB-ODNs. dT 8-mers with the following $3^{\prime}-\mathrm{DPI}_{n}$ conjugate groups were melted with poly $(\mathrm{dA})$ in $140 \mathrm{mM} \mathrm{KCl}, 10$ $\mathrm{mM} \mathrm{MgCl}$, and $20 \mathrm{mM}$ HEPES.HCl (pH 7.2). (1) no DPI, (2) $\mathrm{DPI}_{1}$, (3) $\mathrm{DPI}_{2}$, (4) $\mathrm{DPI}_{3}$. The concentration of each ODN was $2 \times 10^{-6} \mathrm{M}$ and the $\mathrm{A} / \mathrm{T}$ ratio was $1: 1$. Curve 5 shows the melting of the $\mathrm{DPl}_{2}$ conjugate alone in the same buffer. Anomalies in the melting curves may stem from self-association and/or uncharacterized minor transitions. Reprinted from Lukhtanov et al. (1995) with permission from the American Chemical Society.

Table 8.4.1 Melting Temperatures $\left({ }^{\circ} \mathrm{C}\right)$ of MB-ODN Duplexes Formed by Poly $(\mathrm{dA})$ and Poly $(\mathrm{rA})$ with Octathymidylate Strands Terminally Linked to $\mathrm{DPI}_{1-3} \mathrm{MBs}^{a}$

Chemistry of Minor Groove

Binder-

Oligonucleotide

Conjugates

8.4.12

\begin{tabular}{lcccc}
\hline & \multicolumn{2}{c}{ Poly $(\mathrm{dA})$} & \multicolumn{2}{c}{ Poly(rA) } \\
\cline { 2 - 5 } $\begin{array}{l}\text { Octathymidylate } \\
\text { derivative }\end{array}$ & $T_{\mathrm{m}}$ & $\Delta T_{\mathrm{m}}{ }^{b}$ & $T_{\mathrm{m}}$ & $\Delta T_{\mathrm{m}}{ }^{b}$ \\
\hline $\begin{array}{l}\mathrm{dTp})_{8}-\mathrm{O}\left(\mathrm{CH}_{2}\right)_{6} \mathrm{NH}_{2} \\
(\mathrm{dTp})_{8}-\mathrm{DPI}_{1}\end{array}$ & 25 & & 13 & \\
$(\mathrm{dTp})_{8}-\mathrm{DPI}_{2}$ & 54 & 9 & 18 & 5 \\
$(\mathrm{dTp})_{8}-\mathrm{DPI}_{3}$ & $68(65)$ & $43(40)$ & $32(31)$ & $19(18)$ \\
$\mathrm{NH}_{2}\left(\mathrm{CH}_{2}\right)_{6}-(\mathrm{pdT})_{8}$ & 24 & & 12 & \\
$\mathrm{DPI}_{1}-(\mathrm{pdT})_{8}$ & 31 & 7 & 14 & 2 \\
$\mathrm{DPI}_{2}-(\mathrm{pdT})_{8}$ & 49 & 25 & $-c$ & \\
$\mathrm{DPI}_{3}-(\mathrm{pdT})_{8}$ & 68 & 44 & 35 & 23 \\
\hline
\end{tabular}

$a_{\text {The MB conjugates were prepared by method A (Fig. 8.4.5). For comparison, data }}$ obtained with $(\mathrm{dTp})_{8}-\mathrm{DPI}_{3}$ conjugates synthesized by method $\mathrm{B}$ are presented in parentheses.

${ }^{b}$ Difference between ODNs with and without conjugated MBs.

${ }^{c}$ No melting transition was observed. 


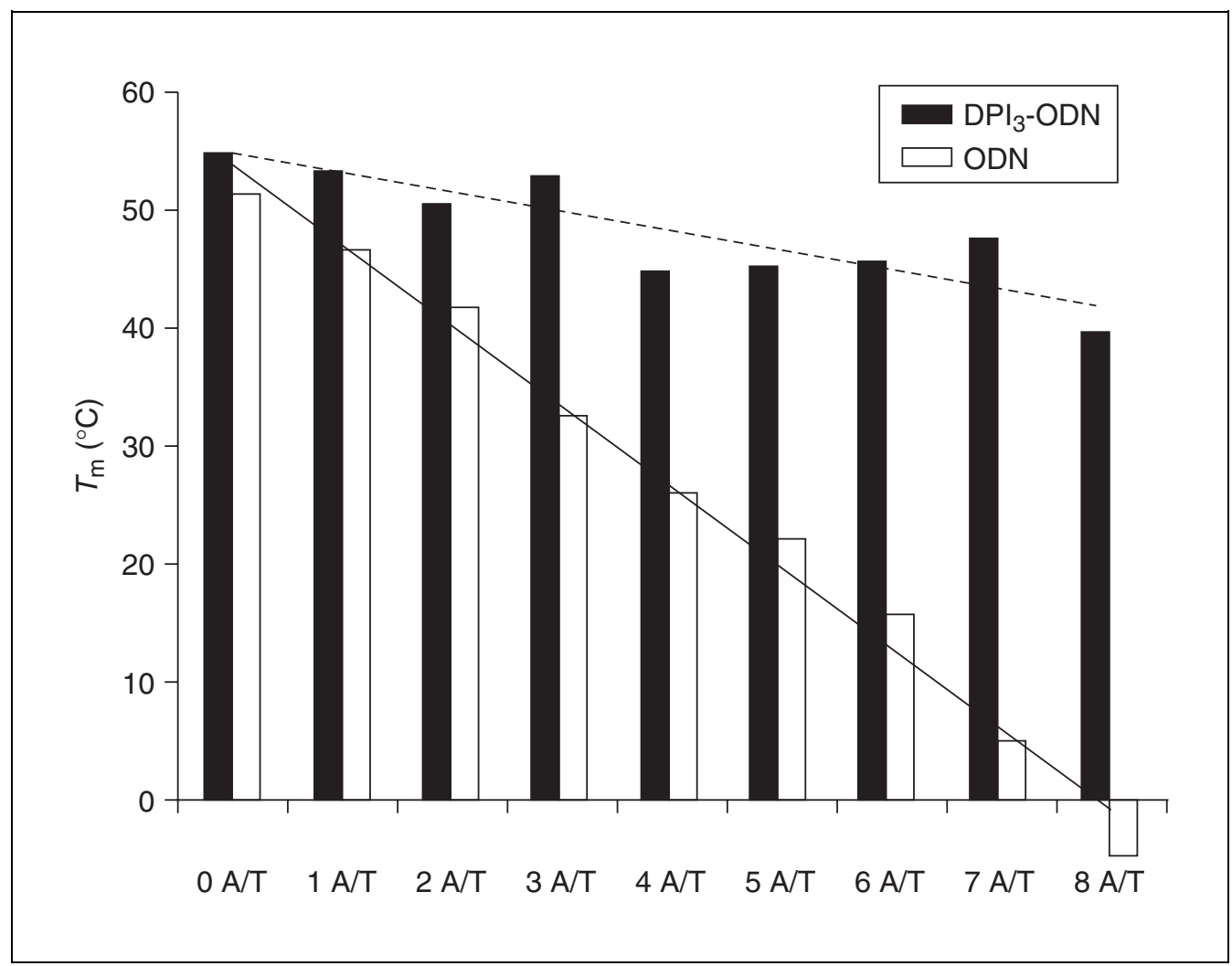

Figure 8.4.8 Effect of $\mathrm{A} / \mathrm{T}$ content on melting temperature $\left(T_{\mathrm{m}}\right)$ of $3^{\prime}$-modified $\mathrm{DPI}_{3}-\mathrm{ODNs}$ versus unmodified 8-mer ODNs is shown. Unmodified ODNs (light bars) show a linear decrease in $T_{\mathrm{m}}$ as $\mathrm{A} / \mathrm{T}$ content increases, while $\mathrm{DPI}_{3}$-ODNs (dark bars) show only a slight drop in $T_{\mathrm{m}}$ ( $T_{\mathrm{m}}$ leveling effect). Sequences ( $5^{\prime}$ to $3^{\prime}$ ) of the 8-mers are as follows: GCCGCCGC, GTCGCCGC, GTCGCTGC, GTCACTGT, GTTACTGT, GTTACTAT, GTTATTAT, ATTATTAT. The concentration of each ODN was $1 \times 10^{-6} \mathrm{M}$, and the buffer used was $0.5 \times$ SSPE.

Figure 8.4.4A. It is noteworthy that $\mathrm{DPI}_{3}$ and $\mathrm{MPC}_{5}$ have similar $T_{\mathrm{m}}$ values when hybridized to poly(dA) targets, and that the crescentshaped conformation of each MB structure fits in a 5- to 6-bp length of dsDNA. The DPI 8-mers described in Figure 8.4.7 were synthesized by postsynthetic conjugation of a $3^{\prime}$ hexylamine-modified ODN with the TFP ester (Fig. 8.4.5, method A). The $\mathrm{DPI}_{3} 8$-mer gave the most stable complex $\left(T_{\mathrm{m}}=68^{\circ} \mathrm{C}\right)$.

Other hybridization properties of DPIODNs are apparent from the list of $T_{\mathrm{m}}$ data in Table 8.4.1. The conjugate formed with the linker structure from method B (synthesis from $\left.\mathrm{DPI}_{3}-\mathrm{CPG}\right)$ showed a similar $T_{\mathrm{m}}\left(65^{\circ} \mathrm{C}\right)$, indicating that the DNA synthesis and ammonia deprotection conditions did not compromise the structural integrity of the $\mathrm{DPI}_{3}$. This was an important finding, since it validated that synthesis of $3^{\prime}$-DPI ${ }_{3}$-ODNs could be efficiently prepared from CPG supports. As described above, this is a major advantage of the $\mathrm{DPI}_{3}-$ type MBs, since it allows a variety of ODN sequences to be easily accessed by automated
DNA synthesis. It was noted that $5^{\prime}-\mathrm{DPI}_{3}-$ ODNs could be prepared from $\mathrm{DPI}_{3}-\mathrm{CPG}$ by using 5' -phosphoramidites instead of the standard 3'-phosphoramidites in DNA synthesis (Lukhtanov et al., 1995).

\section{Backbone Effects on Hybridization}

Another advantage of the $\mathrm{DPI}_{3}-\mathrm{ODNs}$ is improved binding to RNA targets. Both $3^{\prime}$ - and $5^{\prime}-\mathrm{DPI}_{3}$ conjugates increased stability with poly(rA) target strands, but the stabilization was not as great as with DNA targets (Table 8.4.1). Surprisingly, $\mathrm{DPI}_{2}-\mathrm{ODN}$ conjugates formed no detectable hybrids with poly(rA). It is not clear why this phenomenon was observed, but the $\mathrm{DPI}_{2}$ 8-mer ODNs appeared to self-associate as shown in melting curve 5 in Figure 8.4.7. The stabilization of RNA by certain DPI-type MBs has been reported. For example, unconjugated CC-1065 was shown to bind with RNA targets (Kim et al., 1995a) and could improve antisense activity of ODNs (Kim et al., 1995b). DPI ${ }_{3}$-ODN conjugates were studied with other nucleic acid backbones
Nucleic Acid Binding Molecules

8.4.13

Supplement 13 
such as phosphorothioates and 2 - $O$-methyl RNA (Kutyavin et al., 1997). In virtually all systems studied, $\mathrm{DPI}_{3}$-ODNs stabilized duplexes when conjugated at either the $3^{\prime}$ or $5^{\prime}$ terminus. However, the duplexes with DNA targets were much more stable. This is consistent with the preferential binding of low-molecular-weight DPI analogs with B-form DNA duplexes.

\section{Base Composition Effects on Hybridization ( $T_{m}$ Leveling)}

Most of the early studies on MB-ODNs used dT 8-mer ODNs with an MB at either the $3^{\prime}$ or $5^{\prime}$ terminus. Since these early studies were used to optimize the MB conjugation chemistry, it was easier to focus on a single strong binding sequence for development of the synthetic chemistry. However, a G/C-rich 3'-MB conjugate with the sequence CATCCGCT-MB was prepared for both the distamycin-type and the $\mathrm{DPI}_{3}$-type MB (Kutyavin et al., 1997). Melting curve analysis of 8-mer duplexes showed no increase in stability with the distamycin-type MB-ODNs, whereas the $\mathrm{DPI}_{3}-\mathrm{ODN}$ gave a $16^{\circ} \mathrm{C}$ increase in $T_{\mathrm{m}}$. This stabilization of G/Crich duplexes is a major advantage of the $\mathrm{DPI}_{3}$ ODNs.

With the availability of a standardized $\mathrm{DPI}_{3}$ CPG support chemistry, various $\mathrm{DPI}_{3}-\mathrm{ODN}$ sequences could be readily prepared via automated DNA synthesis. A more rigorous study of DNA binding affinity versus base sequence was undertaken. $\mathrm{DPI}_{3}$ molecules have an affinity for A/T-rich sequences, and this same property is observed in the $\mathrm{DPI}_{3}-\mathrm{ODN}$. Since the linker between $\mathrm{DPI}_{3}$ and the ODN is short, the end of the $\mathrm{DPI}_{3}$ does not stretch past six base pairs. If the six terminal bases at the linker end of the ODN are A/T rich, then this duplex will likely make a good $\mathrm{DPI}_{3}$ binding site. Figure 8.4.8 shows the huge increase in affinity that can be attained with $\mathrm{A} / \mathrm{T}$-rich $\mathrm{DPI}_{3}-\mathrm{ODNs}$. The all-A/T DPI ${ }_{3}-\mathrm{ODN}$ had a $T_{\mathrm{m}}$ of $48^{\circ} \mathrm{C}$, whereas the corresponding unmodified ODN had a $T_{\mathrm{m}}$ of $4^{\circ} \mathrm{C}$. The stepwise increase in $\Delta T_{\mathrm{m}}$ as the
Chemistry of Minor Groove

Binder-

Oligonucleotide

Conjugates

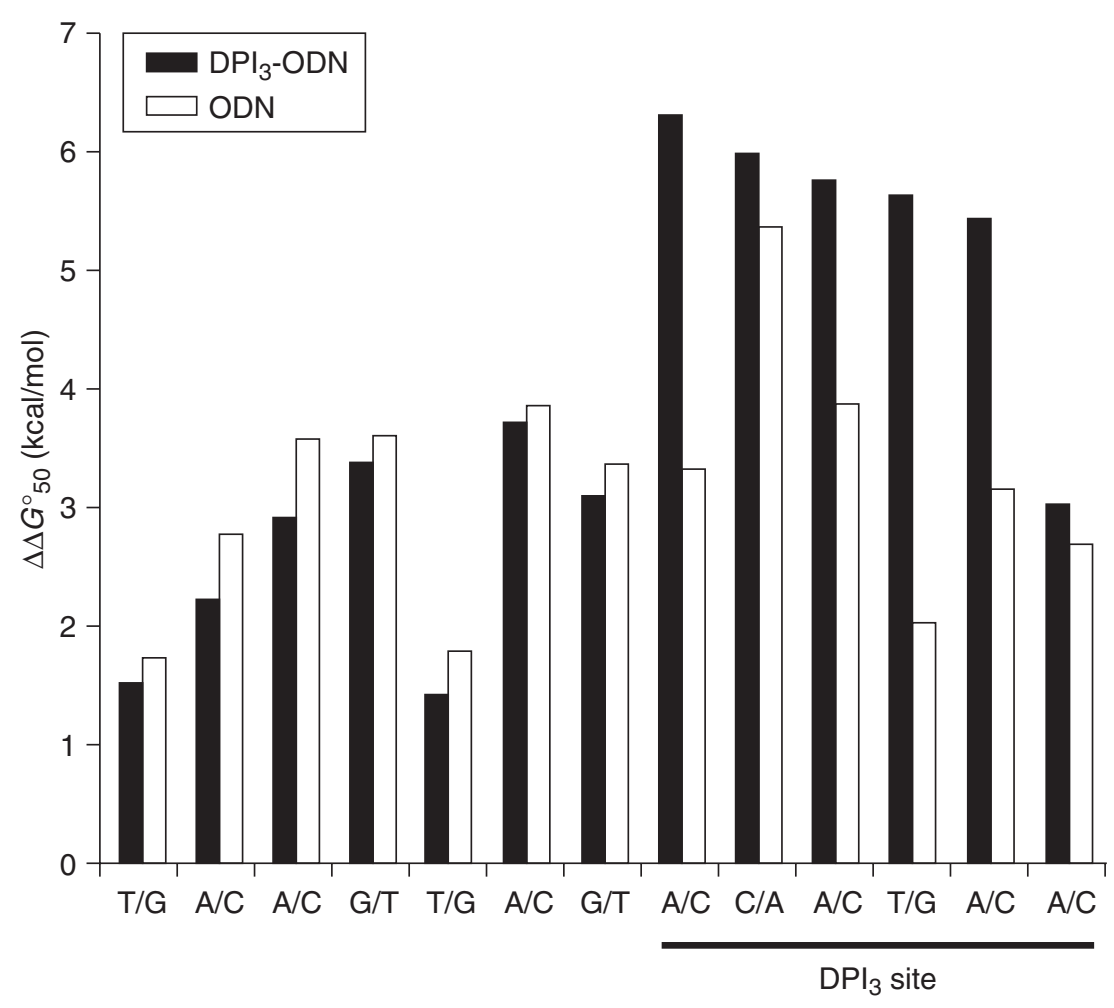

Figure 8.4.9 Relative free energy difference between match and mismatch. Detection of mismatches by a 3'-modified 13-mer $\mathrm{DPI}_{3}$-ODN (light bars) and an unmodified 13-mer ODN (dark bars) for various DNA targets. UV melting experiments were used to calculate a free energy difference $\left(\Delta \Delta G^{\circ}{ }_{50}\right)$ for each mismatch type and location. Mismatch discrimination for each duplex is shown in relationship to the $\mathrm{DPI}_{3}$ binding site. The sequence of the 13-mer is TAAGTAGACATAA. 
Table 8.4.2 Accuracy of Predicted Increases in DNA Duplex Stability for Various Fluorogenic $3^{\prime}-\mathrm{DPI}_{3}-\mathrm{ODNs}$

\begin{tabular}{|c|c|c|c|c|}
\hline Sequence ${ }^{a}\left(5^{\prime}\right.$ to $3^{\prime}$ direction $)$ & $\begin{array}{l}T_{\mathrm{m}}\left({ }^{\circ} \mathrm{C}\right)^{b} \\
\text { ODN }\end{array}$ & $\begin{array}{l}T_{\mathrm{m}}\left({ }^{\circ} \mathrm{C}\right)^{b} \\
\mathrm{DPI}_{3}-\mathrm{ODN}\end{array}$ & $\begin{array}{l}\text { Calculated } T_{\mathrm{m}} \\
\left({ }^{\circ} \mathrm{C}\right)^{c} \mathrm{DPI}_{3}-\mathrm{ODN}\end{array}$ & Error $\left({ }^{\circ} \mathrm{C}\right)$ \\
\hline CTGTAAGTAGATATAAC & 51.8 & 65.9 & 66.7 & 0.8 \\
\hline GGCAAGATATATAG & 50.2 & 66.4 & 65.6 & -0.8 \\
\hline GTGACGCAGATTCC & 61.3 & 77.0 & 75.2 & -1.8 \\
\hline GTAAGTAGACATAAC & 52.1 & 64.6 & 63.3 & -1.3 \\
\hline CAGGGAGCTTTGGA & 59.9 & 74.4 & 71.5 & $-2.9^{d}$ \\
\hline CACTCGTGAAGCTG & 60.9 & 74.0 & 72.3 & -1.7 \\
\hline GTAAGTAGGCATAAC & 55.7 & 66.9 & 66.0 & -0.9 \\
\hline CCGGATGTAGGATC & 57.5 & 69.3 & 70.0 & 0.7 \\
\hline GATTACCTGGATTT & 50.6 & 62.3 & 62.2 & 0.1 \\
\hline CGGCTACAGCTGG & 61.1 & 71.6 & 73.0 & 1.4 \\
\hline GTTCATGGGTGTAAT & 57.5 & 66.9 & 68.8 & 1.9 \\
\hline \multicolumn{5}{|c|}{$\begin{array}{l}{ }^{a} \text { Representative sequences from a list of } 50 \text { test } \mathrm{ODNs} \text { are shown. All } \mathrm{DPI}_{3} \text {-ODNs were modified with } 5^{\prime} \\
\text { fluorescein and a } 3^{\prime} \text { quencher as shown in Figure } 8.4 .10 . \mathrm{DPI}_{3} \text {-ODN sequences contained a G analog (PPG). } \\
{ }^{b} \text { Melting temperatures }\left(T_{\mathrm{m}}\right) \text { of ODNs and } \mathrm{DPI}_{3} \text {-ODNs were determined from } A_{260} \text { melting curves using PCR } \\
\text { buffer and a DNA duplex concentration of } 1 \mu \mathrm{M} \text {. } \\
{ }^{c} \text { Thermodynamic parameters }(\Delta H \text { and } \Delta S) \text { were determined for each duplex sequence using nearest-neighbor base } \\
\text { pair models. Entropy }(\Delta S) \text { for each DPI }{ }_{3} \text { binding site was determined and used to calculate the predicted } T_{\mathrm{m}} \text {. } \\
{ }^{d} \text { Largest error obtained for all sequences tested. }\end{array}$} \\
\hline
\end{tabular}

$\mathrm{DPI}_{3}$ binding site becomes more A/T-rich is especially striking and resulted in a " $T_{\mathrm{m}}$ leveling" effect for this series of 8-mer sequences.

\section{Mismatch Discrimination with DPI3-ODNs}

Short $\mathrm{DPI}_{3}$-ODNs have another advantage for detection of mismatches in DNA targets. As shown in Figure 8.4.9, if there is a mismatch in the DNA duplex, especially in the $\mathrm{DPI}_{3}$ binding site, the $\mathrm{DPI}_{3}$-ODN/DNA duplex is greatly destabilized. This can be used to advantage for detecting certain "difficult" mismatches. For example, T/G mismatches are known to be difficult to detect with natural DNA probes. Figure 8.4.9 compares probe specificity versus mismatch position for 13-mers with and without $\mathrm{DPI}_{3}$ at the $3^{\prime}$ terminus. The higher values for $\Delta \Delta G$ of formation for the $\mathrm{DPI}_{3}-\mathrm{ODN} 13-$ mer indicate higher specificity. The T/G mismatch under the $\mathrm{DPI}_{3}$ site is almost three times easier to detect (i.e., has an almost three-foldhigher $\Delta \Delta G$ ) in comparison to the unmodified ODN.

Note that the comparison of 13-mer $\mathrm{DPI}_{3}$ ODNs in Figure 8.4.9 does not account for the fact that much longer (and less discriminating) unmodified ODNs would be required to reach the $T_{\mathrm{m}}$ of the $\mathrm{DPI}_{3}-\mathrm{ODNs}$. The $T_{\mathrm{m}}$ of the perfect match 13 -mer $\mathrm{DPI}_{3}-\mathrm{ODN}$ is $60^{\circ} \mathrm{C}$, whereas the
$T_{\mathrm{m}}$ of the unmodified ODN is $42^{\circ} \mathrm{C}$. In order to get maximum mismatch detection with the unmodified ODN, the assay would need to be run at a temperature $18^{\circ} \mathrm{C}$ lower than that used for the $\mathrm{DPI}_{3}$-ODN. As pointed out below (see Thermodynamics of Hybridization), hybridization assays such as PCR require the higher temperatures where $\mathrm{DPI}_{3}-\mathrm{ODNs}$ perform best.

\section{Thermodynamics of Hybridization}

The effects of the sequence and structure of $\mathrm{DPI}_{3}$-ODNs on hybridization performance was rigorously examined by UV melting curve analysis. As described above, $\mathrm{DPI}_{3}$-ODNs hybridize to A/T-rich ssDNA targets more strongly than to G/C-rich targets, thus leveling the $T_{\mathrm{m}}$ values of $\mathrm{DPI}_{3}-\mathrm{ODN} / \mathrm{DNA}$ duplexes. $\mathrm{A} / \mathrm{T}$-rich targets require long ODN sequences since A-T base pairs bind more weakly. The shorter $\mathrm{DPI}_{3}-\mathrm{ODNs}$ gave better mismatch discrimination than longer unmodified ODNs as described below. The objective of the authors' research was to develop methods for predicting hybridization properties of $\mathrm{DPI}_{3}$-ODNs and to improve their performance in hybridizationbased assays. Thermodynamic parameters were determined that allow accurate prediction of melting temperatures of DNA duplexes formed with MB probes. Fluorogenic 3'-DPI ${ }^{-}$ ODNs (see next section) were used for these
Nucleic Acid Binding Molecules

8.4.15

Supplement 13 


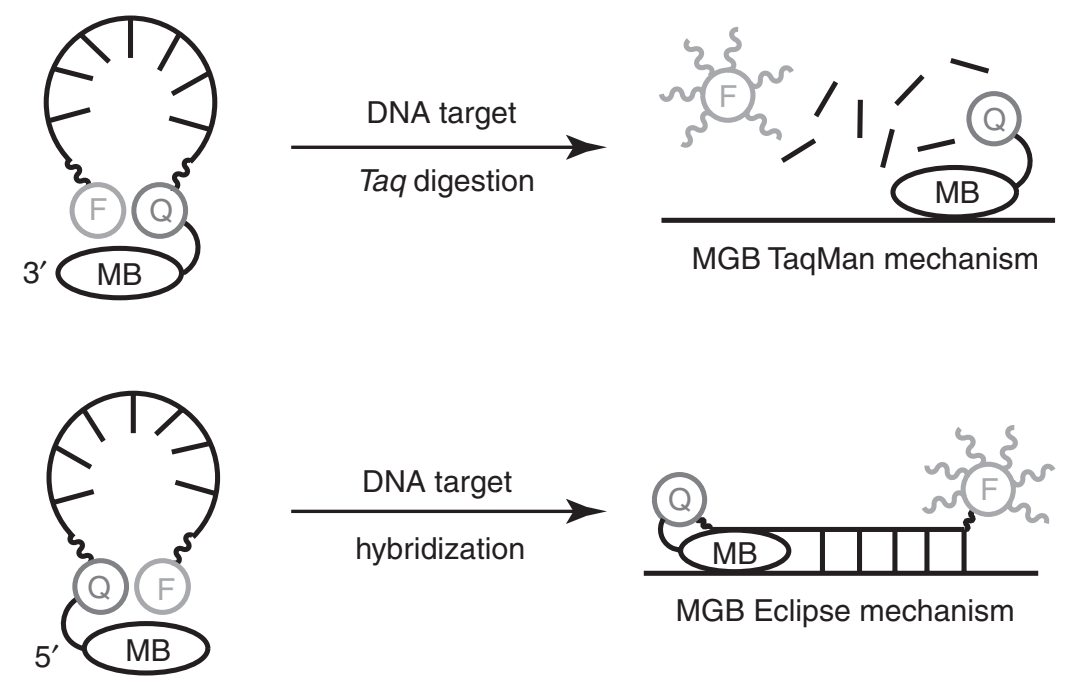

Figure 8.4.10 Typical assay formats for hybridization detection using fluorogenic DNA probes. $F$ is a fluorescent reporter and $\mathrm{Q}$ is a nonfluorescent quencher. Quench release by nuclease digestion (TaqMan mechanism; Roche and Applied Biosystems) or hybridization (Eclipse mechanism; Epoch Biosystems) gives a fluorescent signal. The stylized MB-ODN structure shows a coiled ODN conformation with $\mathrm{MB}, \mathrm{Q}$, and $\mathrm{F}$ in close contact. The two mechanisms are described in detail in Afonina et al. (2002).

experiments since there are commercial applications for PCR probes with these specific structures.

$\mathrm{DPI}_{3}-\mathrm{ODNs}$ hybridize with A/T-rich targets to give B-form DNA duplexes. As described above, the hydrophobic $\mathrm{DPI}_{3}$ molecule stabilizes $\mathrm{DPI}_{3}$-ODN/DNA duplexes due to the increased entropy of the hydrated duplex system. Base pairing is not disturbed in the minor groove binding region ( 5 to $6 \mathrm{bp}$ ) and conformation of the sugar-phosphate backbone is not distorted. Analysis of UV melting curves and Van't Hoff plots showed that the decreased free energy (more negative $\Delta G$ ) of the $\mathrm{DPI}_{3}$ ODN/DNA duplex is mainly due to an increase in entropy (less negative $\Delta S$ ). These entropic parameters were measured for $\mathrm{DPI}_{3}$ ODN/DNA duplexes with varying A/T- and G/C-rich sequences. Specific sequences of ODNs were used to develop parameters for all possible $\mathrm{DPI}_{3}$ binding sites. Since the B-form conformation and natural Watson-Crick bonding are undisturbed for $\mathrm{DPI}_{3}-\mathrm{ODN}$, thermodynamic parameters for DNA duplex formation could be used in the unbound region.

The derived thermodynamic parameters for $\mathrm{DPI}_{3}-\mathrm{ODN} / \mathrm{DNA}$ duplex and natural DNA duplex binding were used to develop computer software that can accurately predict $T_{\mathrm{m}}$ values for fluorogenic $\mathrm{DPI}_{3}-\mathrm{ODNs}$. Additional ther- modynamic parameters were derived for a nonaggregating pyrazolo[3,4- $d]$ pyrimidine guanine analog (PPG) in DNA duplexes since it was found that PPG enhanced hybridization performance of G-rich ODNs and $\mathrm{DPI}_{3}-\mathrm{ODNs}$ (Kutyavin et al., 2002). Table 8.4.2 shows experimental and calculated $T_{\mathrm{m}}$ values for selected sequences. The accuracy of the prediction program is generally within $2^{\circ} \mathrm{C}$. Although the thermodynamic parameters were first derived for $3^{\prime}-\mathrm{DPI}_{3}-\mathrm{ODN} / \mathrm{DNA}$ duplexes, parameters have since been derived for fluorogenic $5^{\prime}-\mathrm{DPI}_{3}-\mathrm{ODN}$ conjugates. Details of these experiments will be described elsewhere. $T_{\mathrm{m}}$ prediction algorithms for fluorogenic $3^{\prime}-$ $\mathrm{DPI}_{3}$-ODNs are incorporated in TaqMan MGB probe design software (Applied Biosystems). Algorithms for fluorogenic $5^{\prime}$ - $\mathrm{DPI}_{3}$-ODNs are incorporated in MGB Eclipse probe design software (Epoch Biosciences).

\section{APPLICATIONS OF DPI3-ODNs IN PCR ASSAYS}

In contrast to longer unmodified ODNs, $\mathrm{DPI}_{3}$-ODNs allow accurate mismatch detection at high temperature. At low temperatures, DNA targets can ball up or aggregate. These intramolecular structures can prevent accurate genetic analysis of many sequences. For instance, PCR is the most widely used DNA 


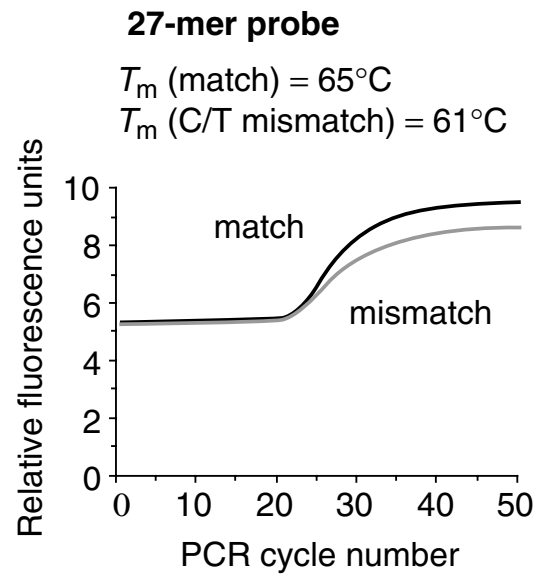

12-mer probe (3'-DPI $)$

$T_{\mathrm{m}}$ (match) $=66^{\circ} \mathrm{C}$

$T_{\mathrm{m}}(\mathrm{C} / \mathrm{T}$ mismatch $)=46^{\circ} \mathrm{C}$

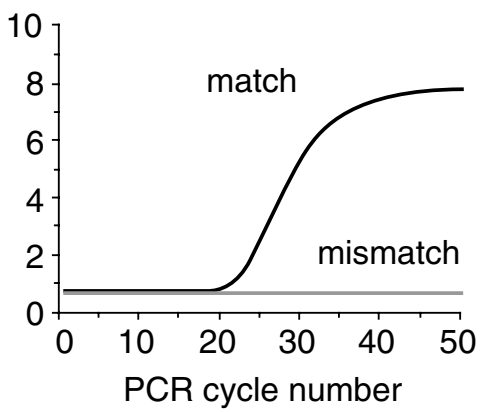

Figure 8.4.11 Effect of $3^{\prime}-\mathrm{DPI}_{3}$ on single-base mismatch discrimination in the TaqMan assay. Fluorogenic 27-mer and 12-mer $\left(3^{\prime}-\mathrm{DPI}_{3}\right)$ probes with similar $T_{\mathrm{m}}$ values were prepared (Kutyavin et al., 2000). The sequence of the 12-mer probe was FAM-GGCAATTIAAAG*-DPI ${ }_{3}$ and the sequence of the 27-mer probe was FAM-GGATCCAAAGAATTGGGCAATTIAAAG*-DPI 3 , where FAM is fluorescein amidite, the underline indicates the site of the $C / T$ mismatch, and $G^{*}$ indicates the attachment point of a fluorescent quencher (TAMRA). Melting studies with mismatched complements showed improved discrimination with the shorter $3^{\prime}-\mathrm{DPI}_{3}$ probe. Fluorogenic PCR was performed with an extension temperature of $60^{\circ} \mathrm{C}$. Each diagram shows a real-time PCR fluorescent curve with either match (upper curve) or mismatch (lower curve) plasmids as templates.

amplification method. PCR requires short DNA primers to bind to DNA targets at high annealing and extension temperatures (ideally $\sim 65^{\circ} \mathrm{C}$ ) to prevent false priming. Although PCR works well, very long primers are sometimes required to bind at these high temperatures. Even at these high temperatures, some undesired complexes can remain in the target or probes. If the DNA target is inaccessible to primers, then PCR can be inefficient.

PCR applications of $\mathrm{DPI}_{3}-\mathrm{ODN}$ probes and primers were explored soon after the $\mathrm{DPI}_{3}$-type MB-ODNs were developed. It was found that 5 '-DPI 3 primers could be extended by Taq polymerase, and primers as short as 8-mers were useful (Afonina et al., 1997). Another application took advantage of the inability of $T a q$ polymerase to efficiently process through a $5^{\prime}$-DPI $_{3}$-ODN probe (Afonina et al., 1996). When Taq polymerase encountered a blocking 5'-MB-ODN “clamp", PCR was arrested. This sequence-specific clamping of PCR with $\mathrm{DPI}_{3}$ ODNs only occurred when Taq polymerase encountered the $\mathrm{DPI}_{3}$-ODN probe from the $5^{\prime}$ end, and only when primer extension temperature was low enough to allow efficient binding of the $\mathrm{DPI}_{3}-\mathrm{ODN}$.

\section{Real-Time PCR with Fluorogenic DPI 3 -ODN Probes}

DNA probes or primers with fluorescent labels have a wide range of applications in molecular biology laboratories. Fluorescence has rapidly replaced radioactivity as a label in hybridization assays. Fluorescence is easily measured, presents few safety hazards, and can be measured in a multiplexed detection scheme, allowing in-process controls or higher assay throughput. Recently, molecular biologists and nucleic acid chemists have developed versatile hybridization assays that use fluorogenic probes. These assays are especially useful for researchers studying clinical samples since the closed-tube format reduces sample handling and possible contamination. Fluorogenic probes such as hairpin probes (Tyagi et al., 1998), 5'-nuclease probes (Livak et al., 1995), or Invader probes (Lyamichev et al., 1999) can be used in thermal-cycling fluorometers for quantitation of DNA samples. Fluorogenic probes can also be used economically with simple fluorescence plate readers for end-point analysis (de Kok et al., 2002). In the real-time PCR assay, fluorescent signal is measured at each PCR cycle and the curve generated from these data can be analyzed to determine the starting copy number of DNA. This technique
Nucleic Acid Binding Molecules

8.4.17

Supplement 15 
has become standard in modern molecular biology (Walker, 2002).

Fluorogenic DNA probes function in one of two molecular mechanisms as shown in Figure 8.4.10. In either format, sensitivity relies on efficient quenching of the intact fluorogenic probes. A molecular fragment with desired fluorescent properties (fluor, F) is linked to the DNA probe of interest, and a quenching molecule $(\mathrm{Q})$ is attached to the other terminus. Quenching of the excited state of the fluor involves fluorescence resonance energy transfer (FRET). FRET has historically been used to measure distances between suitable fluor and quencher pairs (see UNIT 11.10), but has become widely used with fluorogenic probes for DNA detection assays (Didenko, 2001). This quenching mechanism requires the fluor and quencher to pass within a specific distance (the Forster radius; see UNIT 11.10) during the lifetime of the excited state of the fluor. Suitable fluors and quenchers are selected based on overlap of the emission spectrum of the fluor and the absorbance spectrum of the quencher. Recently, the quenching mechanisms of FRET probes have been explored and nonfluorescent quenchers have been described (Johansson et al., 2002).

\section{Improved Sequence Specificity of Fluorogenic DPI 3 -ODN Probes in a Model PCR System}

To demonstrate the utility of fluorogenic $\mathrm{DPI}_{3}$-ODNs in real-time PCR, probes with and without $\mathrm{DPI}_{3}$ were compared in the $5^{\prime}$-nuclease (TaqMan) assay (Kutyavin et al., 2000). In these early experiments, TAMRA was used as a quencher molecule and attached between the ODN and the terminal $\mathrm{DPI}_{3}$ via a 3 '-terminal PPG linker (see UNIT 1.8). Probes were designed to bind to the same strand in the center of an 81-bp PCR product. The model PCR system used two plasmid templates that varied by only a single base pair. Each fully matched probe was designed to have a $T_{\mathrm{m}}$ value close to the optimal temperature of the $\mathrm{Taq}$ polymerase extension step $\left(65^{\circ}\right.$ to $\left.72^{\circ} \mathrm{C}\right)$. Comparison of a 12-mer $\mathrm{DPI}_{3}-\mathrm{ODN}$ with an unmodified 27-mer ODN showed similar $T_{\mathrm{m}}$ values for the matched duplexes, but a dramatic difference in mismatch discrimination (see Figure 8.4.11). The 12-mer $\mathrm{DPI}_{3}-\mathrm{ODN}$ showed a $20^{\circ} \mathrm{C}$ drop in $T_{\mathrm{m}}$ for the mismatch target, whereas the 27-mer ODN showed only a $4^{\circ} \mathrm{C}$ drop in $T_{\mathrm{m}}$. The short $\mathrm{DPI}_{3}$ ODN probe had much better mismatch discrimination than the longer unmodified ODN.
The fluorogenic probes used in Figure 8.4.11 were compared for their ability to function in the $5^{\prime}$-nuclease assay. PCR was conducted with a two-step cycle, with annealing and extension at the same temperature. In separate experiments (Kutyavin et al., 2000), primer extension temperature was varied between $55^{\circ} \mathrm{C}$ and $70^{\circ} \mathrm{C}$, and the $\mathrm{DPI}_{3}-\mathrm{ODN}$ showed excellent discrimination over the entire temperature range. Ideally, the $T_{\mathrm{m}}$ of the probe with perfectly matched template should be slightly higher than the extension temperature, and the $T_{\mathrm{m}}$ of a probe with the single nucleotide mismatched template should be lower. Because of the large $\Delta T_{\mathrm{m}}$ for the $\mathrm{DPI}_{3}$-ODN probes, these criteria were easily met. The real-time PCR fluorescence curves for the $\mathrm{DPI}_{3}-\mathrm{ODN} 12$-mer probe showed excellent mismatch discrimination. In contrast, discrimination by the ODN $27-$ mer probe was difficult to achieve. Some discrimination was seen at $67^{\circ} \mathrm{C}$, but the increase in fluorescence was low. At $65^{\circ} \mathrm{C}$ the 27-mer showed poor discrimination, and at $70^{\circ} \mathrm{C}$ there was no signal.

Another remarkable feature of the $\mathrm{DPI}_{3}-$ ODN probes was the low background fluorescence (at cycle 1). As seen in Figure 8.4.11, the background of the intact $\mathrm{DPI}_{3}-\mathrm{ODN}$ probe was several times lower than that of the 27-mer ODN probe. Quenching of 5'-fluorescein emission by FRET requires close proximity of the reporter and quencher dyes during the excited state lifetime of the reporter fluor. The random coil structure of the probes in solution allows FRET despite the long distance between the dyes (Livak et al., 1995). The lower background observed for the $\mathrm{DPI}_{3}-\mathrm{ODN}$ probe is presumably due to the short probe length, but there are other structural factors that contribute to more efficient quenching (Johansson et al., 2002). As a result, the dynamic range of fluorogenic $\mathrm{DPI}_{3}$ ODN probes in real-time PCR curves is much greater than with conventional unmodified ODN probes.

The short length and efficient quenching of fluorogenic $\mathrm{DPI}_{3}$-ODN probes also make them ideal as "hybridization-triggered" probes (Fig. 8.4.10, Eclipse mechanism). Recently, application of this technology to real-time PCR has been reported (Afonina et al., 2002). Since the 5 - $-\mathrm{DPI}_{3}-\mathrm{ODN}$ Eclipse probes are not digested during PCR (Afonina et al., 1996), the amplified DNA strands can be analyzed in the same wells by fluorogenic melting curve analysis. This allows PCR to be run in standard thermal cyclers, and more accurate data analysis to be 
obtained on various commercial thermal-cycling fluorometers.

\section{SUMMARY}

Studies of MB-ODNs have shown that they can have advantages in comparison to unmodified ODNs. The $\mathrm{DPI}_{3}$-type MB-ODNs are preferred since the conjugation chemistry has been developed to allow rapid synthesis of various sequences. The shorter $\mathrm{DPI}_{3}$-ODNs have advantages for many hybridization assays, especially for A/T-rich DNA targets and detection of single nucleotide polymorphisms (SNPs). The biophysical properties of $\mathrm{DPI}_{3}-\mathrm{ODN}$ s have been elucidated, and this allows the $T_{\mathrm{m}}$ values for specific $\mathrm{DPI}_{3}-\mathrm{ODN}$ sequences to be predicted. Fluorogenic $\mathrm{DPI}_{3}-\mathrm{ODN}$ probes have been developed that show improved performance in real-time PCR assays, and this application is being exploited in modern molecular biology laboratories.

\section{LITERATURE CITED}

Afonina, I., Kutyavin, I., Lukhtanov, E., Meyer, R.B., and Gamper, H. 1996. Sequence-specific arrest of primer extension on single-stranded DNA by an oligonucleotide-minor groove binder conjugate. Proc. Natl. Acad. Sci. U.S.A. 93:3199-3204.

Afonina, I., Zivarts, M., Kutyavin, I., Lukhtanov, E., Gamper, H., and Meyer, R.B. 1997. Efficient priming of PCR with short oligonucleotides conjugated to a minor groove binder. Nucl. Acids Res. 25:2657-2660.

Afonina, I.A., Reed, M.W., Lusby, E., Shishkina, I.G., and Belousov, Y.S. 2002. Minor groove binder-conjugated DNA probes for quantitative DNA detection by hybridization-triggered fluorescence. BioTechniques 32:940-949.

Bailly, C. and Chaires, J.B. 1998. Sequence-specific DNA minor groove binders. Design and synthesis of netropsin and distamycin analogues. Bioconjugate Chem. 9:513-538.

Baird, E.E. and Dervan, P.B. 1996. Solid phase synthesis of polyamides containing imidazole and pyrrole amino acids. J. Am. Chem. Soc. 118:6141-6146.

Boger, D.L. and Johnson, D.S. 1995. CC-1065 and the duocarmycins: Unraveling the keys to a new class of naturally derived DNA alkylating agents. Proc. Natl. Acad. Sci. U.S.A. 92:36423649.

Boger, D.L. and Zhou, J. 1993. CDPI 3 -enediyne and $\mathrm{CDPI}_{3}$-EDTA conjugates: A new class of DNA cleaving agents. J. Org. Chem. 58:3018-3024.
Boger, D.L., Coleman, R.S., and Invergo, B.J. 1987. Studies on the total synthesis of CC-1065: Preparation of a synthetic, simplified 3-carbamoyl1,2-dihydro-3H-pyrrolo[3,2-e]indole dimer/trimer/tetramer (CDPI dimer/trimer/tetramer) and development of methodology for PDE-I dimer methyl ester formation. J. Org. Chem. 52:1521-1530.

Boger, D.L., Invergo, B.J., Coleman, R.S., Zarrinmayeh, H., Kitos, P.A., Thompson, S.C., Leong, T., and McLaughlin, L.W. 1990. A demonstration of the intrinsic importance of stabilizing hydrophobic binding and non-covalent van der waals contacts dominant in the non-covalent CC1065/B-DNA binding. Chem. Biol. Interact. 73:29-52.

Boger, D.L., Boyce, C.W., Garbaccio, R.M., and Goldberg, J.A. 1997. CC-1065 and the duocarmycins: Synthetic studies. Chem. Rev. 97:787828.

Chang, D.K. and Cheng, S.F. 1996. On the importance of van der Waals interaction in the groove binding of DNA with ligands: Restrained molecular dynamics study. Int. J. Biol. Macromol. 19:279-285.

Cory, M. 1995. DNA minor-groove binding compounds as antitumor agents. Cancer Chemotherapeutic Agents: ACS Professions Reference Book Chapter 8:311-344.

de Kok, J.B., Wiegerinck, E.T., Giesendorf, B.A., and Swinkels, D.W. 2002. Rapid genotyping of single nucleotide polymorphisms using novel minor groove binding DNA oligonucleotides (MGB probes). Hum. Mutat. 19:554-559.

Dempcy, R.O., Kutyavin, I.V., Mills, A.G., Lukhtanov, E.A., and Meyer, R.B. 1999. Linkers designed to intercalate the double helix greatly facilitate DNA alkylation by triplex-forming oligonucleotides carrying a cyclopropapyrroloindole reactive moiety. Nucl. Acids Res. 27:29312937.

Dickerson, R.E., Drew, H.R., Conner, B.N., Wing, R.M., Fratini, A.V., and Kopka, M.L. 1982. The anatomy of A-, B-, and Z-DNA. Science 216:475-485.

Didenko, V.V. 2001. DNA probes using fluorescence resonance energy transfer (FRET): Designs and applications. Biotechniques 31:11061121.

Inga, A., Chen, F.X., Monti, P., Aprile, A., Campomenosi, P., Menichini, P., Ottaggio, L., Viaggi, S., Abbondandolo, A., Gold, B., and Fronza, G. 1999. $N$-(2-Chloroethyl)- $N$-nitrosourea tethered to lexitropsin induces minor groove lesions at the p53 cDNA that are more cytotoxic than mutagenic. Cancer Res. 59:689-695.

Johansson, M.K., Fidder, H., Dick, D., and Cook, R.M. 2002. Intramolecular dimers: A new strategy to fluorescence quenching in dual-labeled oligonucleotide probes. J. Am. Chem. Soc. 124:6950-6956.
Nucleic Acid Binding Molecules

8.4.19

Supplement 13 
Kielkopf, C.L., White, S., Szewczyk, J.W., Turner, J.M., Baird, E.E., Dervan, P.B., and Rees, D.C. 1998. A structural basis for recognition of A-T and T-A base pairs in the minor groove of BDNA. Science 282:111-115.

Kim, D.-Y., Shih, D.S., Cho, D.Y., and Swenson, D.H. 1995a. Helix-stabilizing compounds CC1065 and U-71,184 bind to RNA-DNA and DNA-DNA duplexes containing modified internucleotide linkages and stabilize duplexes against thermal melting. Antisense Res. Dev. 5:49-57.

Kim, D.-Y., Swenson, D.H., Cho, D.Y., Taylor, H.W., and Shih, D.S. 1995b. Helix-stabilizing agent, CC-1065, enhances suppression of translation by an antisense oligodeoxynucleotide. $\mathrm{An}$ tisense Res. Dev. 5:149-154.

Kumar, S., Reed, M.W., Gamper, H.B., Gorn, V.V., Lukhtanov, E.A., Foti, M., West, J., Meyer, R.B., and Schweitzer, B.I. 1998. Solution structure of a highly stable DNA duplex conjugated to a minor groove binder. Nucl. Acids Res. 26:831838.

Kutyavin, I.V., Lukhtanov, E.A., Gamper, H.B., and Meyer, R.B. 1997. Oligonucleotides with conjugated dihydropyrroloindole tripeptides: Base composition and backbone effects on hybridization. Nucl. Acids Res. 25:3718-3723.

Kutyavin, I.V., Afonina, I.A., Mills, A., Gorn, V.V., Lukhtanov, E.A., Belousov, E.S., Singer, M.J., Walburger, D.K., Lokhov, S.G., Gall, A.A., Dempcy, R., Reed, M.W., Meyer, R.B., and Hedgpeth, J. 2000. 3'-Minor groove binderDNA probes increase sequence specificity at PCR extension temperatures. Nucl. Acids Res. 28:655-661.

Kutyavin, I.V., Lokhov, S.G., Afonina, I.A., Dempcy, R., Gall, A.A., Gorn, V.V., Lukhtanov, E., Metcalf, M., Mills, A., Reed, M.W., Sanders, S., Shishkina, I., and Vermeulen, N.M. 2002. Reduced aggregation and improved specificity of G-rich oligodeoxyribonucleotides containing pyrazolo[3,4-d]pyrimidine guanine bases. $\mathrm{Nucl}$. Acids Res. 30:4952-4959.

Levina, A.S., Metelev, V.G., Cohen, A.S., and Zamecnik, P.C. 1996. Conjugates of minor groove DNA binders with oligonucleotides: Synthesis and properties. Antisense Nucleic Acid Drug Dev. 6:75-85.

Livak, K.J., Flood, S.J., Marmaro, J., Giusti, W., and Deetz, K. 1995. Oligonucleotides with fluorescent dyes at opposite ends provide a quenched probe system useful for detecting PCR product and nucleic acid hybridization. PCR Methods Appl. 5:357-362.

Lukhtanov, E.A., Kutyavin, I.V., Gamper, H.B., and Meyer, R.B. Jr. 1995. Oligodeoxyribonucleotides with conjugated dihydropyrroloindole oligopeptides: Preparation and hybridization properties. Bioconjugate Chem. 6:418-426.

Lukhtanov, E.A., Kutyavin, I.V., and Meyer, R.B. 1996a. Direct, solid phase assembly of dihydropyrroloindole peptides with conjugated oligonucleotides. Bioconjugate Chem. 7:564-567.
Lukhtanov, E.A., Podyminogin, M.A., Kutyavin, I.V., Meyer, R.B., and Gamper, H.B. 1996b. Rapid and efficient hybridization-triggered crosslinking within a DNA duplex by an oligodeoxyribonucleotide bearing a conjugated cyclopropapyrroloindole. Nucl. Acids Res. 24:683687.

Lukhtanov, E.A., Kutyavin, I.V., Gorn, V.V., Reed, M.W., Adams, A.D., Lucas, D.D., and Meyer, R.B. Jr. 1997. Sequence and structure dependence of the hybridization-triggered reaction of oligonucleotides bearing conjugated cyclopropapyrroloindole. J. Am. Chem. Soc. 119:6213-6225.

Lyamichev, V., Mast, A.L., Hall, J.G., Prudent, J.R., Kaiser, M.W., Takova, T., Kwiatkowski, R.W., Sander, T.J., de Arruda, M., Arco, D.A., Neri, B.P., and Brow, M.A. 1999. Polymorphism identification and quantitative detection of genomic DNA by invasive cleavage of oligonucleotide probes. Nature Biotechnol. 17:292-296.

Mikheikin, A.L., Zhuze, A.L., and Zasedatelev, A.S. 2001. Molecular modelling of ligand-DNA minor groove binding: Role of ligand-water interactions. J. Biomol. Struct. Dyn. 19:175-178.

Milesi, D., Kutyavin, I., Lukhtanov, E.A., Gorn, V.V., and Reed, M.W. 2000. Synthesis of oligonucleotide conjugates in anhydrous dimethyl sulfoxide. Methods Enzymol. 313:164-173.

Rajur, S.B., Robles, J., Wiederholt, K., Kuimelis, R.G., and McLaughlin, L.W. 1997. Hoechst 33258 tethered by a hexa(ethylene glycol) linker to the 5 -termini of oligodeoxynucleotide 15 mers: Duplex stabilization and fluorescence properties. J. Org. Chem. 62:523-529.

Robles, J. and McLaughlin, L.W. 1997. DNA triplex stabilization using a tethered minor groove binding Hoechst 33258 analogue. J. Am. Chem. Soc. 119:6014-6021.

Robles, J., Rajur, S.B., and McLaughlin, L.W. 1996. A parallel-stranded DNA triplex tethering a Hoechst 363258 analogue results in complex stabilization by simultaneous major groove and minor groove binding. J. Am. Chem. Soc. 118:5820-5821.

Savage, H.F.J. 1993. Water structure. In Water and Biological Macromolecules (E. Westhof, ed.) pp. 3-39. CRC Press, Boca Raton, Fla.

Singh, M.P., Joseph, T., Kumar, S., Bathini, Y., and Lown, J.W. 1992. Synthesis and sequence-specific DNA binding of a topoisomerase inhibitory analog of Hoechst 33258 designed for altered base and sequence recognition. Chem. Res. Toxicol. 5:597-607.

Sinyakov, A.G., Lokhov, S.G., Kutyavin, I.V., Gamper, H.B., and Meyer, R.B. 1995. Exceptional and selective stabilization of A-T rich DNADNA duplexes by $N$-methypyrrole carboxamide peptides conjugated to oligodeoxynucleotides. $J$. Am. Chem. Soc. 117:4995-4996.

Szewczyk, J.W., Baird, E.E., and Dervan, P.B. 1996a. Cooperative triple-helix formation via a minor groove dimerization domain. J. Am. Chem. Soc. 118:6778-6779. 
Szewczyk, J.W., Baird, E.E., and Dervan, P.B. 1996b. Sequence-specific recognition of DNA by a major and minor groove binding ligand. Angew. Chem. Int. Ed. Engl. 35:1487-1489.

Thuong, N. and Helene, C. 1993. Sequence-specific recognition and modification of double-helical DNA by olgionucleotides. Angew. Chem. 32:666-690.

Tyagi, S., Bratu, D.P., and Kramer, F.R. 1998. Multicolor molecular beacons for allele discrimination. Nature Biotechnol. 16:49-53.

Walker, N. 2002. A technique whose time has come. Science 296:557-559.

Wiederholt, K., Rajur, S.B., Giuliano, J. Jr., O’Donnell, M.J., and McLaughlin, L.W. 1996. DNAtethered Hoechst groove binding agents: Duplex stabilization and fluorescence characteristics. $J$. Am. Chem. Soc. 118: 7055-7062.
Wiederholt, K., Rajur, S.B., and McLaughlin, L.W. 1997. Oligonucleotides tethering Hoechst 33258 derivatives: Effect of the conjugation site on duplex stabilization and fluorescence properties. Bioconjugate Chem. 8:119-126.

Zimmer, C. and Wahnert, U. 1986. Nonintercalating DNA-binding ligands: Specificity of the interaction and their use as tools in biophysical, biochemical and biological investigations of the genetic material. Prog. Biophys. Mol. Biol. 47:31-112.

Contributed by Igor Kutyavin, Sergey

Lokhov, Eugene Lukhtanov, and

Michael W. Reed

Epoch Biosciences

Bothell, Washington
Nucleic Acid

Binding Molecules

8.4.21 